\title{
New Approaches to Photodynamic Therapy from Type I, II and III to Type IV Using One or More Photons
}

\author{
Kathrin M. Scherer*a, Roger H. Bisby ${ }^{\mathrm{b}}$, Stanley W. Botchway ${ }^{*}{ }^{*}$, and Anthony W. Parker ${ }^{\mathrm{c}}$ \\ ${ }^{*}$ MRC Laboratory for Molecular Cell Biology (LMCB), Faculty of Life Sciences, University College London, \\ UK, Phone: +44(0)207 679 7274, Email:k.scherer@ucl.ac.uk; ${ }^{b}$ Biomedical Science Research Centre, School \\ of Environment \& Life Sciences, University of Salford, Salford, UK; ${ }^{c}$ Research Complex at Harwell, Central \\ Laser Facility, STFC Rutherford Appleton Laboratory, Harwell Campus, Didcot, UK
}

\begin{abstract}
Photodynamic therapy (PDT) is an alternative cancer treatment to conventional surgery, radiotherapy and chemotherapy. It is based on activating a drug with light that triggers the generation of cytotoxic species that promote tumour cell killing. At present, PDT is mainly used in the treatment of wet age-related macular degeneration, for precancerous conditions of the skin (e.g. actinic keratosis) and in the palliative care of advanced cancers, for instance of the bladder or the oesophagus. Due to a lack of phase III clinical trials and limitations of light penetration to deeper lying tumours (in excess of $1 \mathrm{~cm}$ ), PDT is still not used as a first line cancer treatment, which is surprising given the first clinical trials by Dougherty's group dating back to the 1970's. However research continues to demonstrate the potential benefits of PDT and the need to stimulate funding and uptake of clinical studies using next generation photosensitizers offering advanced targeted delivery, improved photodynamic dose combined with modern light delivery technologies. This review surveys the available PDT treatments and emerging novel developments in the field with a particular focus on two-photon techniques that are anticipated to improve the effectiveness of PDT in tissues at depth and on next generation drugs that work without the need of the presence of oxygen for photosensitization making them effective where hypoxia has taken hold.
\end{abstract}

Keywords: Photodynamic therapy (PDT), photosensitizer, two-photon, combretastatin, anticancer, Type IV

\section{INTRODUCTION TO PDT}

More than 200 types of cancers are known to date with different levels of severity and a variety of characteristics $[1$, 2]. This creates a need for novel and advanced treatment modalities beyond the classical approaches of surgery, chemotherapy and radiotherapy. PDT is such an alternative treatment modality, which on its own or in combination with the classical treatments aims to provide improved clinical outcomes and long term remission for cancer patients. The main advantages of clinically approved PDT include its minimal invasiveness (minimized scarring) compared with surgical tumour removal, reduced likelihood to develop multidrug resistance (MDR) and selectivity towards malignant cells restricting unwanted side-effects towards collateral healthy tissue compared with chemotherapy [3-6].

Traditionally the term PDT means the use of light of a specific wavelength (commonly provided by a red lamp or a laser) and a photoactivatable drug (referred to as the photosensitizer (PS)) that upon absorption of light undergoes electronic excitation and generates either directly or indirectly cytotoxic agents (see Figure 1A) that include for example reactive oxygen species, sensitized usually via a triplet energy transfer (see section 4.1 Photochemistry of photosensitizers). The highly reactive oxygen species (ROS) have the ability to locally destroy cancerous tissue in a patient [4, 5, 7-12]. In the clinic PDT treatment commonly consists of two stages (Figure 1B).

Following PDT treatment photosensitivity of the skin can occur, lasting from a few days up to a few weeks because of slow excretion of PS molecules from the patient's body. This prolonged sensitivity to light usually forces the patient to avoid direct exposure to sunlight until the drug is discharged. Accurately specifying the dosimetry of PS administered and light dose can help to reduce this unwanted side-effect $[3$, 10, 13-15]. Another major limitation of PDT is the depth the activating light can penetrate into tissue at the excitation wavelength $[4,16]$, as well as the inactivity of many photosensitizers in hypoxic environments, which restricts formation of ROS, such as commonly found in tumour cores. The therapeutic outcome of PDT depends on a wide range of treatment parameters including the light source, light fluence $\left(\mathrm{W} / \mathrm{cm}^{2}\right)$, the method used to illuminate the tissue, tissue type, tissue oxygenation, specificity of the drug to a certain cancer type, and the PS [17]. 
A DIRECT

\begin{tabular}{l} 
No tissue oxygen required \\
\hline Type IV \\
Irradiation induces a structural change \\
within the PS allowing it to bind to
\end{tabular}

INDIRECT

Oxygen essential its subcellular target.

Type I

Electron transfer to oxygen from an excited PS leads to the formation of radical species (e.g. $\mathrm{OH}^{\circ}, \mathrm{O}_{2}{ }^{-{ }^{-}}$and others), which oxidise biomolecules leading to cell death.

Examples:

Porphyrin-based PSs, hypericin, furocoumarins

Mic Photoisomerization
of combretastatins

\section{Type III}

Triplet-doublet interaction between the activated PS and native free radicals leading to cytotoxicity.

Example:

Antioxidant Carrier Sensitizers (ACS), such as substituted porphyrins

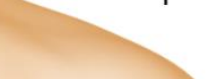
- 12 Light
+ PS

Type II

Singlet oxygen is formed by energy transfer from the excited triplet PS to ${ }^{3} \mathrm{O}_{2}$ causing cell death, e.g. by oxidising lipids.

Target cell or tissue Examples: See Type I

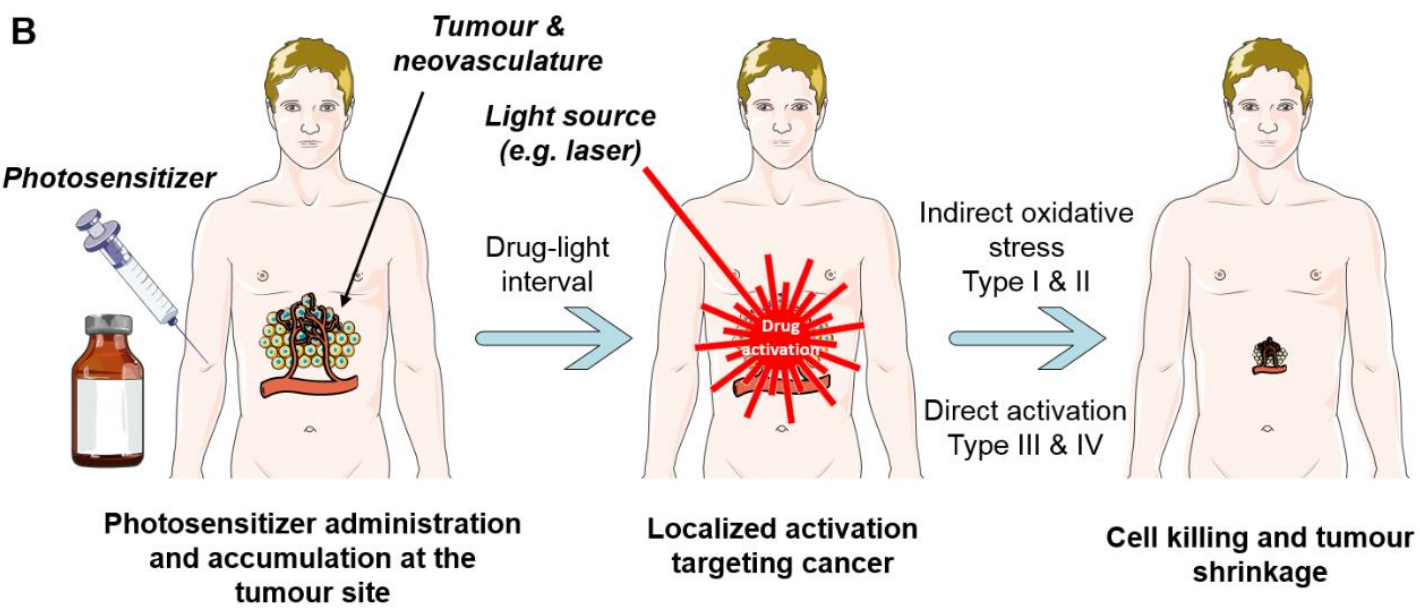

Figure 1 Different types of photodynamic therapy (PDT) based on the reaction mechanism of the photosensitizer (PS) used and key steps of PDT in the clinic. A There exist direct (oxygen-independent) and indirect (requiring oxygen) mechanisms of photosensitization in PDT depending on the PS being used. Most PSs used in the clinic demonstrate the Type II mechanism, but other PSs have been proposed that use the direct Type III and IV mechanism and are also effective in hypoxic tissues, where Type I and II photosensitization is limited. B In the clinic PDT treatment commonly consists of two stages. First the patient is administered a suitable dose of a light-activatable photosensitizer (PS) (usually by intravenous injection or topical as a cream), which is allowed to accumulate in the body with selectivity to the tumour site. The accumulation can take minutes to days depending on the PS used and location at the target site. Secondly, PS accumulation is followed by irradiation directly at the location of the diseased tissue site (e.g. tumour) with an intense light source (usually a laser) of a defined wavelength matching the PS absorption spectrum thus leading to the formation of an excited state. A dominant form of decay of the excited state PS is to transfer energy (sensitize) molecular oxygen so that it comes into contact with or reacts with cellular constituents generating reactive oxygen species (ROS) such as singlet oxygen and oxygen radicals (Type I \& II). Singlet oxygen is highly reactive and cytotoxic, and hence causes damage to the irradiated cells eventually leading to selective apoptosis or necrosis in the treated tissue and tumour shrinkage [4, 5, 7, 15, 18-22].

PDT was originally developed for the localized treatment of solid tumours, but presently it is more commonly used in the clinical treatment of early cancers of the lung, oesophagus (Barrett's oesophagus), skin (actinic keratosis, squamous and basal cell carcinoma, but not melanoma), bladder, breast, cervix, mouth, intestines and lungs. The effectiveness of PDT towards other cancers e.g. of the head and neck, bile duct, pancreas, prostate, and brain is being investigated in clinical studies. PDT is primarily applied to the targeted treatment of superficial cancers (e.g. of the skin) and cancers that are easy to reach by endoscopic fibres, as light penetration in tissue, particularly in the visible 
wavelength range is limited. Other conditions that have been successfully treated using PDT include macular degeneration, particularly using two-photon PS activation, and bacterial infections [3-5, 20, 23-28].

Although PDT is successfully applied to treat a range of cancers it can also have significant drawbacks depending on the PS and light source used, location of the malignant lesion or tissue oxygenation level. PDT PSs often lack selectivity towards neoplastic tissues, which may lead to the generation of reactive oxygen species and cellular damage (burns, swelling, pain) in surrounding healthy tissues upon excitation [14, 17, 28, 29]. The highly localized nature of PDT makes it mostly unsuitable for the treatment of metastases [5].

In the UK the National Institute for Health and Clinical Excellence (NICE) has approved PDT for use in certain types of skin cancer and internal cancers that can be reached by laser light within a few millimetres of the tumour particularly when located near the lining of internal organs and for superficial lesions. In the clinic, PDT is mainly used in palliative care or to cure early cancers and some precancerous conditions. In the treatment of more advanced cancers PDT is often used in combination with other treatment modalities with the aim of tumour size reduction and symptom relief. It is still very much at a developmental stage for the treatment of many conditions and is hence often given to patients as part of a clinical trial. Unfortunately there is only a small number of advanced (phase III) trials because of funding cuts. PDT can be offered in an outpatient service, which is cost-effective and saves the patient a hospital stay [5, 20, 27]. A recent review focuses specifically on the use of PDT for the treatment of malignant brain tumours and provides a detailed and up-to-date summary of clinical investigations undertaken by numerous groups around the World [30]. It also highlights the difficulty in fully assessing the clinical impact of PDT because of the lack of control studies. Even though PDT is recognised by the NHS (National Health Service, UK) as an effective, licensed cancer treatment according to the information published on their official UK website concern is expressed about unproven and unlicensed versions of PDT that are being marketed by some private clinics in the UK and overseas (Mexico and China). These include so called "nextgeneration PDT (NGPDT)" and "sonodynamic therapy (SDT)", applying ultrasound to activate a PS [27].

Nevertheless there is still a significant amount of research ongoing in the development of novel PSs and their targeted delivery to tumours as can be seen by the number of publications in the field that have been continuously increasing since the 1960's (Figure 2).

It is only through the continued and indeed sustained fundamental development of novel PSs and treatment protocols that PDT will become a viable technique to treat cancer. This review surveys the use of PDT in the clinic and covers the current developments in the field. We emphasize and put into context new approaches using two-photon, as opposed to single photon, methods and identify new potential sensitizers that introduce a novel Type IV PDT mechanism that have greater potential to target cancer in hypoxic environments.

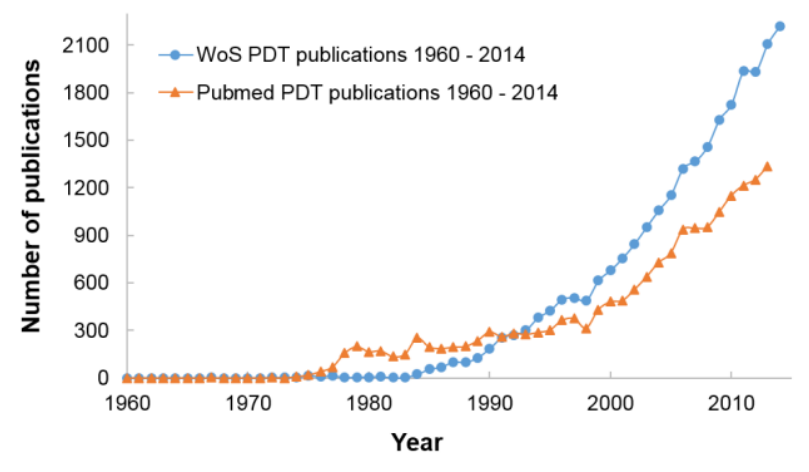

Figure 2 Development of publication numbers per year on photodynamic therapy since 1960 as found on Web of Science (WoS, filter to include: articles, reviews and patents) and NCBI PubMed (Search: photodynamic therapy).

\section{HISTORY OF PDT}

The use of sunlight ("heliotherapy") to treat conditions such as vitiligo, rickets, psoriasis, psychosis, and even skin cancer was recognized by ancient civilisations including the Egyptians, Indians, Chinese and Greek [7, 31]. Nonetheless it took until the late $18^{\text {th }}$ century before an early form of phototherapy for the treatment of smallpox and cutaneous tuberculosis using an artificial red light source was developed by Niels Finsen. For his work using a "Finsen" lamp the Danish scientist was awarded the Nobel Prize in 1903 [31]. Around the same time in 1900 Oscar Raab, a student of Professor Herman von Tappeiner, observed cell death in paramecia cultures when treating them with a combination of acridine red and light irradiation. In the same laboratory the term "photodynamic action" was coined when it was recognized that oxygen was essential to induce the observed cell killing. This discovery triggered a substantial amount of research into various aspects of PDT including the mechanisms of photodynamic processes, new PSs and clinical studies. The first PDT clinical trials were reported in 1905 using eosin and Magdala red as PSs. The PS hematoporphyrin, a precursor of porphyrin which is still commonly used in photodynamic treatments to date, was first used in preclinical experiments on mice by Hausmann in 1911. Two years later the German scientist, Friedrich Meyer-Betz administered himself with $200 \mathrm{mg}$ of the PS intravenously to test its effectiveness in humans. He experienced swelling and soreness in body parts that were exposed to sunlight.

The first detailed studies of the effects of oxygen presence and the role of reactive singlet oxygen $\left({ }^{1} \mathrm{O}_{2}\right)$ in PDT of cancer cells using hematoporphyrin derivative (HpD) as PS were reported by Moan et al. in the late 1970's. They reported that lower $\mathrm{O}_{2}$ concentrations resulted in a reduced PDT effect and that hypoxic tumour cells demonstrated resistance to the PDT. They hence suggested to enrich hypoxic tissues with oxygen during the treatment. Another group reported on patients with oesophageal cancer who showed improved outcomes when the treatment was carried out under increased pressure ( 2 absolute atmospheres) compared with conventional PDT under atmospheric pressure [32].

The discovery that porphyrins preferentially localize and fluoresce in tumour tissue, the purification of $\mathrm{HpD}$ from crude hematoporphyrin [33-37] and the fact that it could be 
activated by red light led to the first trials using $\mathrm{HpD}$ as a PS by Thomas Dougherty's group in the 1970s. Exciting results were obtained in the treatment of cutaneous and subcutaneous malignant tumours with tumour regression being observed in 111 cases. However, photosensitization of the skin for up to 6 weeks following administration of the PS was found to be a major side-effect of this treatment $[4,7$, 31, 32, 38, 39]. Despite the promising results achieved by Dougherty and his co-workers, the first controlled clinical trials using $\mathrm{HpD}$ as PDT PS were only started in the mid1980's - mid-1990's by Quadra Logic Technologies (QLT) Photo Therapeutics (Canada) and American Cyanamid (NY). These clinical studies led to the approval of the PS Photofrin ${ }^{\circledR}$ (purified derivative of $\mathrm{HpD}$ ) for the palliative treatment of bladder cancer in 1993 and later oesophageal, cervical and lung cancer in a few countries [7, 10]. Since then PDT has also been approved for the clinical treatment of conditions other than cancer such as wet age-related macular degeneration (AMD) using Visudyne $® ~(2001)$. By 2009 a range of other PSs had been approved by the FDA including Foscan ${ }^{\circledR}$, Levulan ${ }^{\circledR}$, Metvix ${ }^{\circledR}$ and Hexvix ${ }^{\circledR}[7]$.

\section{MECHANISMS OF PDT}

\subsection{Photochemistry of photosensitizers}

There exist two distinct approaches to PDT, direct and indirect, the terms defining the chemical involvement of the PS and cellular entity. The most established clinically are the indirect mechanisms, Type I and II. Many of these PSs show a combination of Types I and II oxygen-dependent reaction pathways. Types III and IV rely on the direct activation of the photosensitizer that once activated requires no secondary oxygen-dependent reactions to induce cell death (Figure 3). unsaturated lipids eventually leading to cell death. In type II mechanisms, singlet oxygen is formed by energy transfer from the excited state PS (e.g. porphyrins) to molecular oxygen. On a photochemical basis Type II photosensitization is initiated by the absorption of a photon of light by the PS, thereby lifting it from its ground $\left(\mathrm{S}_{0}, 2\right.$ paired electrons with opposite spin) to an excited electronic state $\left(S_{1}\right.$, one electron transferred to higher energy molecular orbital). Relaxation from the $S_{1}$ state back to the ground state can progress via different pathways, such as the emission of a photon (fluorescence), heat (non-radiative decay) or alternatively intersystem crossing (ISC) to the more stable triplet state (inverted electron spin), which has a comparatively long lifetime ( 100 nano- to several microseconds). If oxygen $\left(\mathrm{O}_{2}\right)$ is present the triplet state PS may transfer the excess energy to the ground state molecular oxygen (triplet oxygen, ${ }^{3} \mathrm{O}_{2}$ ) leading to the formation of singlet oxygen $\left({ }^{1} \mathrm{O}_{2}\right)$. Singlet oxygen has a relatively short nanosecond $(\sim 10-320 \mathrm{~ns})$ lifetime in biological systems and hence has a short radius of action $(10-55 \mathrm{~nm})$ through diffusion, thus the intracellular PS localization is important in achieving efficient PDT. Type II reactions are thought to be the most common pathway in photodynamic reactions. In Type III reactions a tripletdoublet interaction between the PS and free radicals takes place exerting a cytotoxic effect towards intracellular structures without the need for oxygen. This mechanism is thought to compete with Type I and II photosensitization. Type III PSs are usually Antioxidant Carrier Sensitizers (ACS), also called Modified Type I (MTO) PSs, which combine properties leading to the efficient generation of

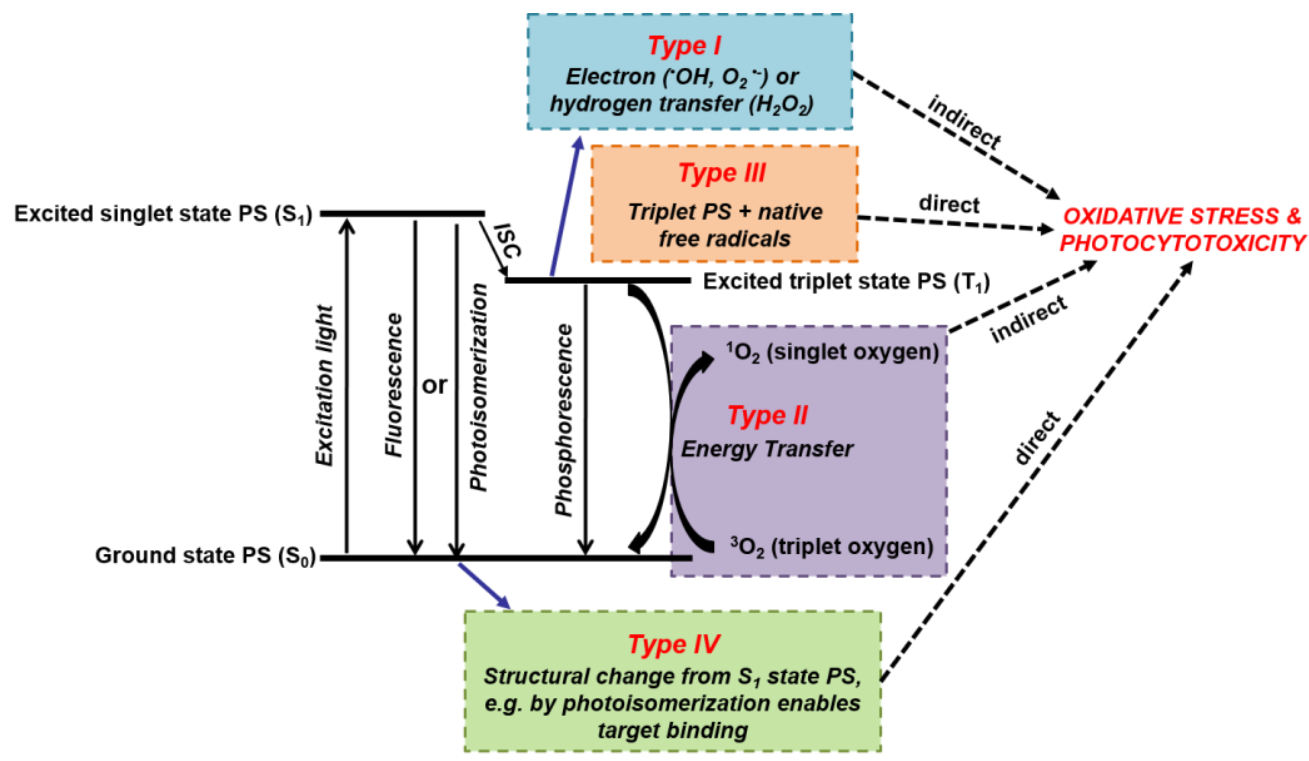

Figure 3 Simplified Jablonski diagram showing the electronic energy levels and the underlying photochemical mechanisms of PDT indicating indirect processes that require the presence of tissue oxygen (Type I \& II), as well as direct mechanisms in which no oxygen is required (Type II and IV) and the PS interacts directly with its subcellular target to induce cell killing. Type I and II mechanisms frequently occur at the same time with Type II usually being the dominating process (ISC $=$ intersystem crossing).

In Type I photodynamic processes radical species $\left(\mathrm{OH}^{*}\right.$, $\mathrm{O}_{2} \cdot{ }^{--}$and others) are formed by electron transfer to oxygen from an excited PS (e.g. furocoumarins). The resulting reactive oxygen species (ROS) oxidize intracellular biomolecules such as nucleic acids, amino acids or from the molecular backbone of originally active PSs used in clinical PDT, such as substituted porphyrin derivatives [5, $10,15,17,19,24,26,28,29,40-44]$. Currently novel types of pro-drugs such as combretastatins, discussed fully in section 4.4, are emerging which can be directly photo- 
activated by multiphoton excitation without the need for the presence of oxygen within the target tissue (see the section on Alternative Strategy for Two-photon Phototherapy (2PPDT) without ROS below). We suggest here a novel Type IV mechanism will be described in detail below (section 5.4). In brief it involves a PS that cannot bind its molecular target and only upon excitation with light undergoes intramolecular remodelling (by photoisomerization) that than facilitates binding of the activated PS to its cellular target site.

\subsection{Action of PDT at the tissue and cellular level}

Over the years there has been a wide range of studies investigating the interaction and distribution of light in tissues, this being fundamental to the successful activation of PSs in vivo. The Patterson group started studying the light propagation within tissues in the 1980's when they realized that an understanding of light-tissue interactions is critical to ensure that sufficient light reaches the treatment site as well as to obtain precise dosimetry for PDT. Their early models (using Monte Carlo simulations) were based on the use of $630 \mathrm{~nm}$ light on tissues in combination with the PS HpD. Absorption and scattering are considered the two main processes leading to light attenuation in tissues, which are highly heterogeneous turbid media. The fluence rate of light at a specific wavelength and its depth distribution are characteristic for each tissue type and depend on pigmentation levels [43, 45-49]. Wavelengths in the nearinfrared (NIR) region (typically $600-1100 \mathrm{~nm}$ ) penetrate deepest into biological tissues. This wavelength range, where tissues are most transparent is called the "tissue window" (see Figure 4C). At shorter wavelengths (e.g. UV region) endogenous chromophores, such as haemoglobin, myoglobin, cytochromes, nicotinamides, flavins and melanin, as well as some pigments such as bilirubin might absorb the excitation light before it reaches the PS at which it is targeted. Hence light penetration into tissues at $\sim 630 \mathrm{~nm}$ is limited to $\sim 1-3 \mathrm{~mm}$. At longer wavelengths (> $1000 \mathrm{~nm}$ ) the absorption by water will prohibit the delivery of light deep inside tissues. At high PS concentrations the so called "self-shielding" (the absorption of light by the PSs itself) may also impair penetration deep into tissues. Unfortunately the longer the wavelength of the excitation light the lower is its energy (photon energy), which restricts its potential to excite a one-photon process due to molecular systems lacking optical absorption on going from the red to nearinfrared wavelengths. A way around this is the use of twophoton (or multiphoton) excitation (2PE), achieved by using a femtosecond pulsed Titanium:sapphire laser with high peak powers (Figure 4) $[4,5,16,28,43,50,51]$ (see sections 5.2 and 5.3 for more details).

A

multiphoton photochemistry
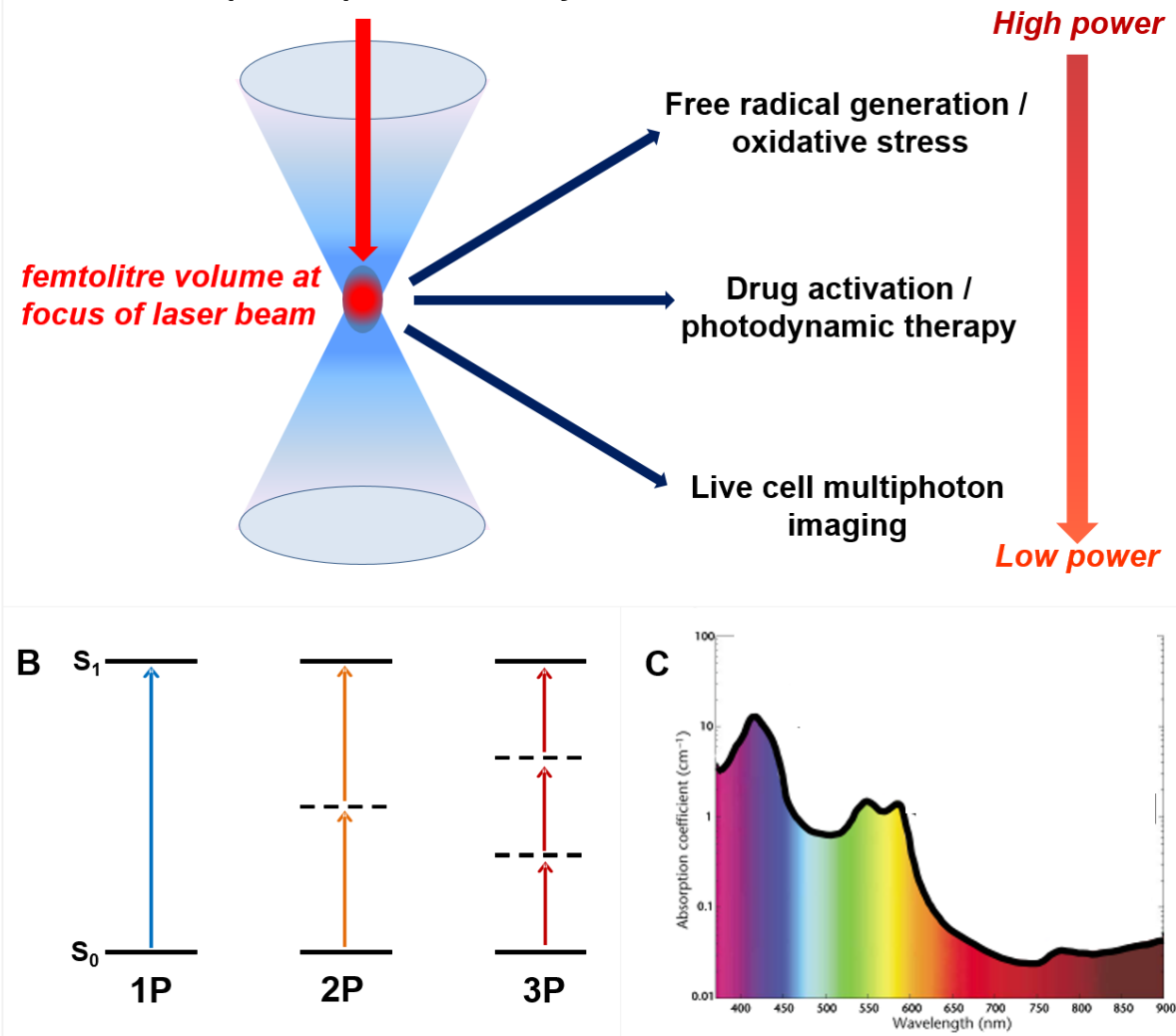

Figure 4 Multiphoton excitation of tissues in the near-infrared reduces scattering and hence improves light penetration and localised light delivery. A Nonlinear processes in the focal volume of a multiphoton microscope depending on the energy delivered by a high peak power femtosecond pulsed laser [52]. B Excitation of a PS to the first excited singlet state (S1) by either one-photon (1P), two-photon (2P) or three-photon (3P) absorption. Virtual states are indicated by dashed lines. For example, in principle an excited state formed by absorption at $300 \mathrm{~nm}$ may also be generated by simultaneous absorption of two photons at $600 \mathrm{~nm}$ or three photons at $900 \mathrm{~nm}$, although the efficiency (photon absorption cross section) for excitation falls dramatically from $1 \mathrm{P}$ to $3 \mathrm{P}$ excitation. C Absorption spectrum of tissue, showing the "tissue window" in the region of $650-900 \mathrm{~nm}(\mathbf{C}$ is adapted from Weissleder and Ntziachristos (2003) [53]). 
Following PDT treatment be it single or more photon induced cell killing is thought to be brought about by three connected mechanisms, including direct cytotoxicity of reactive species towards tumour cells, shutdown of the tumour vasculature which may lead to hypoxia in the tumour and an inflammatory immune response. Since there are several processes involved in causing PDT induced cell killing it is not surprising that any of the three commonly known cell death mechanisms, namely apoptosis, necrosis or autophagy can be triggered [5, 10, 23, 26, 54]. Confocal microscopy and Förster Resonance Energy Transfer (FRET) imaging on cultured cells demonstrated that common PDT PSs are found to localize in different subcellular structures such as the plasma membrane (Photofrin $\left.{ }^{\circledR}\right)$, mitochondria (phthalocyanine Pc4), lysosomes, nucleus, endoplasmic reticulum or the Golgi apparatus [5, 23, 26, 43, 55].

The extent to which each cell death pathway is triggered depends on the PS type, dose and intracellular localization, as well as the tissue type, tissue oxygenation levels and the light dose used. Therefore the accurate prediction of the treatment outcome is very challenging $[10,23,26]$.

The effect that PDT has on the formation of blood vessels was first described in 1989 when it was shown that in many cases endothelial cells of the tumour vasculature may be the primary target of PDT in vivo. There have also been indications that hypoxia, nutrient depletion and oxidative stress in tumours is caused by a PDT induced shutdown of the tumour vasculature. This may not only induce secondary necrosis, but also lead to the overexpression of vascular endothelial growth factor (VEGF) to make up for the loss of blood vessels. Hence the combination of PDT with antiangiogenic agents has been suggested to improve PDT treatment outcomes [5, 23, 26, 54].

Furthermore several groups report that PDT triggers an inflammatory immune response at the tumour site. Efforts to improve tumour control using a combination of PDT in conjunction with immunotherapy to enhance the therapeutic response may prove to be beneficial $[10,51,54,56]$. It is generally believed that apoptosis is the main cell death pathway following PDT and can be triggered by treatment of low light doses. Apoptosis is also thought to cause lower inflammation levels than PDT-induced necrosis and may lead to antitumor immunity. Necrosis is often observed when using higher light doses in PDT, which inactivates enzymes such as caspases [5, 23].

PSs localized in the plasma membrane have been shown to preferentially induce necrotic cell death pathways which is not surprising due to membrane disintegration and the resulting depletion of intracellular ATP. Photosensitizers that are primarily localized in mitochondria (e.g. benzoporphyrin derivatives) frequently induce apoptosis by activation of caspases and cytochrome c [26, 43]. Overall the consensus is that apoptosis and necrosis have the same initial triggers, but the presence of caspases determines which cell death pathway the treated cells will undergo [23]. In some cases autophagy was also found to inhibit or enhance cell death after PDT [26]. Lipophilic PSs generally accumulate in a range of intracellular membranes. Pyropheophorbide-methyl ester (a synthetic derivative of Chlorophyll a) has for instance been reported to accumulate in the endoplasmic reticulum, Golgi apparatus, lysosomes and mitochondria. Photosensitizers that selectively localize in lysosomes have a higher tendency to aggregate and are hence seen to induce cell killing following irradiation with a significantly lower efficiency than agents that are found in other organelles. Targeted PSs that are conjugated to receptor ligands are commonly seen to trigger the endosomal-lysosomal pathway following internalization [43]. In 2000 Dahle et al. showed by in vitro experiments that not only cells directly affected by PDT undergo cell death, but also cells that are adjacent to them can suffer lethal cell damage ("bystander effect") [57]. More recently an opposite "bystander effect" leading to an increase in cell proliferation in HeLa cells at the single cell level under a low dose of protoporphyrin IX (PpIX) sensitized ROS was reported by the Ogilby group [58].

\section{TECHNOLOGICAL CHALLENGES AND DEVELOPMENTS IN PDT}

\subsection{Progress in photosensitizer (PS) development}

The most common clinically used PSs for PDT to date are molecules with a tetrapyrrole backbone such as porphyrins (irradiation at $\sim 630 \mathrm{~nm}$ ) and its analogues including benzoporphyrins, chlorins, bacteriochlorins, pheophorbide $\alpha$, phthalocyanines and texaphrins. However, much research activity has been devoted to demonstrating PSs based on other molecular structures for both pre-clinical and clinical studies, e.g. fullerenes [17, 43, 59-61].

To date a range of PSs has been approved for the treatment of cancer and other conditions in the clinic. Photofrin ${ }^{\circledR}$ (trade name for the water-soluble hematoporphyrin derivative HpD or porfimer sodium) was the first PS agent to be approved by the U.S. Food \& Drug Administration (FDA) for clinical use in the treatment of superficial bladder cancer in the early 1990s. It is the one most commonly used PS for the clinical treatment of neoplastic lesions such as oesophageal, head and neck, skin and some lung cancers to date, despite the fact that it causes long lasting photosensitivity in patients. Other hematoporphyrin derivatives that were clinically evaluated for the treatment of various cancers and other conditions such as bacterial infections include Photosan ${ }^{\circledR}[62,63]$ and Photogem ${ }^{\circledR}[64,65]$.

This was followed by the approval of the chlorine based PS Foscan ${ }^{\circledR}$ (temoporfin, excitation at $652 \mathrm{~nm}$ ), which proved successful in the treatment of skin, lung, bile duct and head and neck cancer, as well as other chlorin-based photosenstitizers including HPPH, SnEt2 (Puryltin), Talaporfin (L511, MACE, NPe6) and chlorin e6polyvinylpyrrolidone (Photolon $\left.{ }^{\circledR}\right)$ and derivatives for the treatment of a variety of neoplasms $[5,51,66,67]$. The nonfluorescent PS precursor 5-aminolevulinic acid (5-ALA, trade name Levulan $\left.{ }^{\circledR}\right)$ enhances the intrinsic production of protoporphyrin IX (PPIX) in mitochondria, which is activated by light illumination $(\sim 635 \mathrm{~nm})$ following accumulation at the treatment site leading to the effective generation of reactive oxygen species within treated cells and triggering cell death [17, 68,69]. The clinical use of topically applied 5-ALA for PDT was first introduced in 1990 [70] and followed by a wide range of clinical and preclinical studies for the PDT treatment of bladder cancer [7173], chronic polyarthritis [74], malignant glioma [75], nonmelanoma skin cancers such as actinic keratosis (in combination with fluorescence dosimetry) [69, 76], Barret's oesophagus and even multidrug resistant leukemia, the latter 
without much success [77]. In 2013 Bader et al. reported a clinical trial using hexaminolevulinate (HAL), a 5-ALA derivative, for the PDT of bladder cancer in humans. HAL activation was achieved using incoherent white-light $(380-$ $700 \mathrm{~nm}$ ) delivered through a $1.5 \mathrm{~mm}$ diameter quartz fibre (2-6 W transmission) integrated in a flexible irradiation catheter. HAL PDT showed good efficiency and minor reversible bladder irritability [78].

Other PSs and precursors that are available pre-clinically or in the clinic include Metvix (methylaminolevulinic acid) for the treatment of the skin conditions actinic keratosis and basal cell carcinoma, LS11 (talaporfin sodium), which is undergoing trials for the treatment of colorectal cancer, glioma and hepatocellular cancer and Tookad (Padoporfin, a Pd-bacteriopheophorbide, $763 \mathrm{~nm}$ ) for the deep vasculartargeted PDT of prostate cancer $[5,51,66]$. There has been a considerable effort to develop PSs with further red shifted absorption spectra to improve their activation at depth within tissues. One of the most successful examples for these efforts are phthalocyanine based systems, of which some derivatives show selective accumulation in tumours. They are non-toxic in their ground state and efficiently generate long lived triplet states and ROS leading to cell killing. The phthalocyanine Pc4 (silicon phthalocyanine, $675 \mathrm{~nm}$ ) entered the clinic where it is used for the treatment of cutaneous Tcell lymphoma. Several water-soluble phthalocyanines showed promising PDT efficiency, as well as naphthocyanines which absorb at longer wavelengths (740 $780 \mathrm{~nm})$. It is hoped that the longer excitation wavelength would allow treatment at greater depth in tissues [5, 9, 59]. The texaphyrin Antrin ${ }^{\circledR}$ (Motexafin lutetium, $732 \mathrm{~nm}$ ) is another long wavelength PS that received clinical approval for the treatment of breast and prostate cancer [5, 79-81]. The natural product hypericin has been suggested as PS for a less invasive PDT treatment of recurrent head and neck squamous cell carcinomas, because of its ROS generation efficiency, tumour selectivity, fluorescence imaging capabilities and low dark toxicity. The PDT efficiency of hypericin excited at $593 \mathrm{~nm}\left(150 \mathrm{~mW}\right.$, up to $\left.60 \mathrm{~J} / \mathrm{cm}^{2}\right)$ using a $\mathrm{Nd}$ :YAG laser was tested in vitro and in vivo delivering evidence that it might be a clinically useful PS [82, 83]. Erythrosine is another potentially useful PS for PDT that accumulates in mitochondria as was shown on premalignant and malignant oral cell lines [84]. PDT is currently most successfully used in the palliative treatment of age-related macular degeneration (AMD) using the PS Visudyne ${ }^{\circledR}$ (verteporfin, $690 \mathrm{~nm}$ ), a derivative of benzoporphyrin, for which it was approved by the FDA in 2000 [4, 5, 10, 20, 24, $28,59,85]$. The combination of conventional PDT PSs with different synergistic drugs has been found to be beneficial to treatment outcomes. Experiments on human breast cancer cells demonstrated that cell killing and therefore PDT efficacy can be significantly increased by synergistic treatment with the glycolysis antagonists 2-deoxy-glucose or 3-bromopyruvate, but the underlying mechanism for this remains unclear [86]. The administration of calcitrol, an activated derivative of Vitamin D3, prior to 5-ALA delivery on squamous skin cancer in mouse models increased the accumulation of protoporphin IX in the tumours and hence the efficiency of 5-ALA-PDT [18]. Combining the conventional PDT treatment with the administration of VEGF has been shown to improve the treatment outcomes with PDT by preventing the formation of tumour neovasculature [5, 23].

From a biological point of view appropriate PSs should display low dark-toxicity, no or low photosensitization of the skin or other unwanted side-effects, rapid and selective uptake into target tissues (tumours), as well as reproducible application as part of a PDT protocol. Biophysically an ideal PS should firstly strongly absorb light at a specific wavelength in the red or NIR region $(650-850 \mathrm{~nm})$ of the spectrum, where light penetrates deeper into tissues, secondly display the efficient generation of cytotoxic species, such as reactive oxygen species (ROS) upon irradiation or as some newer PSs, such as combretastatins, lead to a directly acting drug without the generation of ROS, and lastly exhibit high photostability and demonstrate fluorescence to allow monitoring of their uptake into tumours. From a pharmaceutical viewpoint other advantageous features are simple large scale synthesis, good amphiphilicity (water-solubility for delivery and lipophilicity for targeting), chemical stability, limited aggregation, and rapid break-down into non-toxic metabolic products and excretion from the patient's body after the PDT treatment [3$5,15,19,25,28,42,43,59]$. As yet there exists no optimal PDT PS that matches all of the desired requirements and therefore the development of useful new and clinically relevant PSs is essential.

Photosensitizers can be broadly divided into three categories, namely first, second and third generation PSs. First generation PSs such as Photofrin ${ }^{\circledR}$ and $\mathrm{HpD}$ were found to lead to extended skin photosensitivity and are often given as part of a palliative care pathway [5, 42]. To overcome the undesired photosensitization caused by first generation PSs and shift the PS activation to longer wavelengths second generation PSs (e.g. chlorins, bacteriochlorins and phthalocyanines) were developed. Third generation PSs were designed to improve selective tumour targeting and drug accumulation by conjugating common PSs to carriers such as cholesterol, antibodies, and liposomes and therefore reduce unwanted damage to healthy tissues [5, 42, 69, 78]. The section on targeted PDT below (4.7) will cover these developments in more detail.

\subsection{Light sources for PDT}

The light source chosen for PDT treatment has a significant effect on the results that can be achieved. The choice of light source depends on its cost, reliability, size, available fluence rate (light dose), the PS used, the location of the disease site, as well as on the treatment depth inside tissue that needs to be achieved [5, 32, 69]. Ideally excitation wavelengths in the red or NIR ("tissue window") are best, as the penetration depth in tissues is improved compared to the $\mathrm{UV}$ or visible range. The main types of light sources that can be used for PDT are lasers, LEDs and filtered lamps (e.g. fluorescent tubes, metal halide, xenon arc, high pressure and incandescent filament lamps) $[10,28,69]$. Since the invention of the Finsen lamp there has been much technological development leading to improved light sources. Early light sources that are mainly used for dermatological applications were often conventional white light lamps used in combination with filters to obtain PS activation at a certain wavelength. Overall the most common light source used in PDT are lasers which deliver monochromatic, coherent light and hence facilitate light 
dosimetry. Dye lasers, pumped by a tuneable argon-ion laser ( $5-10 \mathrm{~W})$, that can be matched to the excitation wavelength of the PS (e.g. $630 \mathrm{~nm}$ for HpD) were commonly used clinically from the late 1970's until the early 1980's. In the 1980s Q-switched solid-state frequency-doubled neodymium-doped yttrium aluminium garnet Nd:YAG (KTP (Potassium titanyl phosphate for the second harmonic frequency conversion)) lasers became the standard light source for PDT, since they can provide high energy pulses and are more reliable than the previously used dye lasers. For two-photon applications shorter pulse lasers are required and tuneable mode-locked $(\sim 70-80 \mathrm{MHz}$ repetition rate) femtosecond pulsed $(\sim 150-200 \mathrm{fs})$ Titanium:sapphire lasers that provide high peak powers (tens of $\mathrm{kWs}$ ) are usually the light source of choice. The disadvantages of some of these advanced lasers is that they are rather expensive, bulky and may rely on external water cooling and a non-domestic (3phase) power supply. Furthermore the wavelength tuning can be complicated and may make these lasers less user friendly and suited to the clinical environment. More recently semiconductor diode lasers have become commercially available which generally come at a considerably lower cost than pumped dye lasers, as well as with automated dosimetry and power calibration features. Furthermore their relatively small size makes them more mobile. They do not rely on external water-cooling, are very reliable and can be powered from the domestic mains and are hence easier to maintain. The major limitation of diode lasers is that they are restricted to one wavelength (e.g. $630 \mathrm{~nm}$ ) and need to be carefully chosen depending on the PS being used. The development of laser diodes with multiple wavelengths is highly desired [10, $28,32,68,87]$.

In some cases light emitting diodes (LEDs) may be used as alternative low cost light sources that provide narrow spectral bandwidths and high fluence rates for PS excitation in superficial cancers, such as skin lesions. LED arrays can be configured easily allowing to accurately define irradiation areas of different geometries, e.g. linear arrays can be used endoscopically [10, 28, 69].

When lasers are used the light is often delivered to the tissue of interest through optical fibres coupled to the laser. Optical fibres also benefit from being readily incorporated into an endoscopic device making the light source easily inserted into areas such as the lungs, oesophagus, digestive tract and the bladder for PDT. Additionally inflatable catheters that are coated with a scattering material on the inside are available for improved light delivery, e.g. in bladder cancer. Implanting light sources in solid tumour for deep tissue treatment has also been proposed [5, 21, 28, 32].

To make the light delivery to tissues for fluorescence diagnostics and PDT more efficient different groups have been working towards the development of minimally invasive endoscopic probes. One such minimally invasive and simple contact endoscopic probe with an outer diameter $<1.5 \mathrm{~mm}$ that is inserted inside a conventional biopsy needle has been presented Göbel et al. (2012). Their probe delivers a field of view of up to several hundred microns with a pixel resolution of $\sim 4 \mu \mathrm{m}$ determined by the distance of fibres within the fibre bundle. Using an in vivo animal model they were able to simultaneously detect and image the fluorescence of deep seated brain tumour tissue and its vasculature [88].

\subsection{Two-Photon PDT (2P-PDT)}

The use of two-photon excitation (2PE) of PSs in the NIR between 600 - 1100 nm ("tissue window", Figure 4C) has been suggested as an innovative approach compared with conventional PDT. The main advantage of using 2PE in PDT is the significantly improved penetration depth of the excitation light in tissues compared with UV or visible light, which is strongly absorbed by endogenous chromophores such as haemoglobin or melanin [17, 28, 29, 51, 85, 87, 89]. In the life sciences two-photon and multiphoton excitation with NIR light has been successfully used for the imaging of thick biological specimens with reduced photo-damage and improved 3D sectioning compared to conventional scanning confocal microscopy $[17,87,90]$. Exposure of a PS to ultrashort (< 1 picosecond, ps) pulses of NIR light allows efficient "simultaneous" absorption of two photons by the chromophore in the ground state leading to the same excited state as commonly achieved by one-photon excitation (Figure 4B), as long as the overall energy provided is equivalent. Hence PS activation is also followed by the same photodynamic processes normally induced by one-photon excitation, but with improved treatment depth and selectivity to the treatment area $[5,17,25,28,51,87]$. Other advantages of $2 \mathrm{PE}$ are the highly localized light delivery restricting PS excitation to a very small (femtolitre) confined three dimensional volume and therefore reduction of damage to collateral healthy tissue or potential to target individual tumour blood vessels. Compared with one-photon excitation for PS activation laser-induced hyperthermia and therefore phototoxicity is reduced when using 2PE, as NIR light scattering and absorption in tissues is lower compared with the absorption of UV or visible light by biological molecules $[5,17,25,28,29,50,51,85,87,89,91]$. Furthermore previously unsuitable PSs with excitation in the UV may now be explored by the $2 \mathrm{P}$ or multiphoton process using visible and NIR femtosecond light.

There exist two potential types of two-photon PDT (2PPDT), type one being simultaneous (resonant) and the other two-photon/two colour [28]. Here we will focus on the more common type of two-photon absorption for PS activation. The 'simultaneous' absorption of two photons (within $10^{-15}$ s) was first theoretically predicted by Maria Göppert-Mayer in 1931, but it was not demonstrated experimentally until the development of the first lasers in the 1960's due to the large light intensities needed to trigger this low probability photophysical and photochemical process [92]. The twophoton absorption cross-section of a molecule is a measure of the efficiency with which it will undergo a two-photon absorption process, and the higher it is the higher will be the chance of a two-photon process taking place. The twophoton absorption cross-section $\left(\sigma_{2}\right)$ is measured in GöppertMayer units $\left(1 \mathrm{GM}=10^{-50} \mathrm{~cm}^{4} \mathrm{~s}_{\text {photon }}{ }^{-1}\right.$ molecule $\left.^{-1}\right)[28$, $85,87,89,93]$. For example the widely studied PS Photofrin has a two-photon absorption cross-section of only $3 \mathrm{GM}$ at $800 \mathrm{~nm}$ [94], whereas molecules engineered for 2PA have cross-section values in the region of $10^{3}-10^{4} \mathrm{GM}$ (see below).

The "simultaneous" absorption of two photons of NIR light (longer wavelength, less energy) by the ground state PS is a non-linear two-photon process leading to the generation of a singlet excited state via a short-lived virtual intermediate state $\left(10^{-15} \mathrm{~s}\right)$. Usually "simultaneous" $2 \mathrm{PE}$ is achieved using 
short light pulses of $\leq 100$ fs with high peak powers (from mostly tunable femtosecond mode-locked Titanium:sapphire laser, but more recently also pulsed diode and fibre lasers) at approximately twice the wavelength required to achieve onephoton excitation. Two-photon photoactivation at depth in tissues using fs-lasers for excitation may still be limited when using conventional PSs (e.g. porphyrins) due to their usually small two-photon absorption cross-sections (3 - 16 GM depending on derivative [95]) and the oxygen depth profile in tissues. As mentioned earlier photosensitization with clinically used PSs relies on Type II mechanism which requires the presence of oxygen, but tumour cores are mostly hypoxic (reduced oxygen) once they outgrow a certain size and the tumour neovasculature cannot supply sufficient oxygen to their centre anymore $[5,17,28,50,85,87]$.

Over the last two decades the idea of using two photons of light instead of one to activate PSs in PDT at improved depths in tissues started to attract researchers' attention and led to the development of novel PSs and light sources optimized for 2PE. A key issue regarding the implementation of two-photon methods is the need to improve the understanding of the depths at which PDT drugs can be photoactivated and the photodynamic dose. In terms of single photon activation the attenuation length is a key parameter describing the distance into the tissue or media where the applied light is reduced to approximately $37 \%$. This parameter depends on numerous factors, including drug, ranging from $6.5 \mathrm{~mm}$ to $\sim 1 \mathrm{~mm}$ for excised tumour and brain respectively using $600-700 \mathrm{~nm}$ light [30]. The ability to use further red-shifted wavelengths has potential benefits. To our knowledge the first studies investigating the use of 2PE for PS excitation were reported in the 1980's. Andreoni et al. (1982) described the use of two near-UV photons (10 ns pulsed nitrogen laser, $337 \mathrm{~nm}, \sim 250 \mathrm{~kW}$ peak power, $30 \mathrm{~Hz}$ repetition rate, $20 \mathrm{~mW} / \mathrm{cm}^{2}$ peak irradiation intensity) to excite $\mathrm{HpD}$ and achieve the PDT effect on rat thyroid epithelial cells [96]. They did not fully exploit the potential of 2PE because the advantage of increased depth of PS activation is better suited when using red or NIR light, as discussed above, is absorbed significantly less by intrinsic chromophores and also benefits from being scattered less within tissue. Shortly after Bodaness and co-workers reported the 2PE of the PS HpD using a Q-switched Nd:YG laser at $1064 \mathrm{~nm}$ [97] or an alexandrite laser at $750 \mathrm{~nm}$ in solution [93] in 1985. The first demonstration of 2PE on in vitro cultured oesophagus cancer cells by a Q-switched $\mathrm{Nd}$ :YAG laser emitting at $1064 \mathrm{~nm}$ for deeper activation depth in PDT of HpD dates back to 1986 [98] and was followed by investigations using the even more efficient two-photon PS pheophorbide a [99]. Almost a decade later the use of 2P-PDT in the treatment of bacterial infections (Salmonella typhimurium) using psoralen derivatives activated by irradiation with a pulsed mode-locked Ti:sapphire laser in vitro was successfully demonstrated [87].

It was soon recognized that commonly used PSs such as Photofrin ${ }^{\circledR}$ have too low two-photon absorption crosssections ( 1 - $100 \mathrm{GM})$, require extended illumination with a tightly focused laser beam, and are therefore unsuited for the development of clinical 2P-PDT [5, 7, 28, 50, 87, 89, 100]. Hence there has been much activity by way to develop novel PSs with improved two-photon absorption properties whilst at the same time retaining good pharmacological properties for their clinical application. Some molecular design features are considered to enhance two-photon absorption properties of organic molecules including the insertion of long electronrich $\pi$-conjugated chains, substitution with electron donating and accepting groups to increase intramolecular charge transfer properties and maintaining a planar molecular structure [50, 85, 101]. Some approaches towards the implementation of 2P-PDT and preparation of optimized two-photon PSs are discussed in the following.

In 1997 Bhawalker and his group reported the synthesis of a novel promising dye optimized for two-photon absorption called 4-[N-(2-hydroxyethyl)-N(methyl)aminophenyl]-4'-(6-hydroxyhexyl sulfonyl)stilbene (APSS). The molecule was shown to have a high two-photon absorption efficiency at $800 \mathrm{~nm}$ excitation (two-photon absorption coefficient $\beta=1.45 \mathrm{~cm} / \mathrm{GW}$ ) and to transfer its energy to a PS in solution leading to singlet oxygen generation by indirect activation in presence of molecular oxygen [102]. Four years later another group demonstrated that singlet oxygen was efficiently generated by excitation of 4-(diphenylaminostilbene)-substituted porphyrin-based PSs molecularly designed for enhanced two-photon absorption at $780 \mathrm{~nm}$ (within the "tissue window") using a 150 femtosecond pulsed laser [50]. The development of other 2PPDT agents such as lipophilic quadrupolar chromophores carrying anthracenyl and dibromobenzene residues [103] and hydrophilic conjugated porphyrin dimers [104, 105] with realistic and practical $2 \mathrm{PA}$ cross-sections having at least $>100$ GM (e.g. 8,000 - 17,000 GM for the porphyrin dimers), good photostability and high light absorptivity within the "tissue window" have also been reported. Other porphyrin-based PS with two-photon absorption crosssections of $\sim 2000$ GM bearing targeting peptide chains were described by Starkey et al. [51] (Figure 5A).

The quadrupolar chromophores demonstrated effective cell killing upon $2 \mathrm{PE}$ at $820 \mathrm{~nm}$ and the conjugated porphyrin dimers were shown to be suitable for 2P-PDT in in vivo AMD models [103-105]. Dahlstedt et al. (2009) investigated the effects of 2P-PDT using a range of conjugated porphyrin dimers with high two-photon absorption cross sections up to $17,000 \mathrm{GM}$. They found that $\mathrm{P}_{2} \mathrm{C}_{2}$-NMel was the most efficient dimer demonstrating effective two-photon adenocarcinoma cell killing when excited using a pulsed femtosecond laser at $920 \mathrm{~nm}(3.6-$ $6.8 \mathrm{~mW}, 300 \mathrm{fs}, 90 \mathrm{MHz})$. Unfortunately the irradiation time required to achieve $50 \%$ cell killing using $\mathrm{P}_{2} \mathrm{C}_{2}-\mathrm{NMel}(180 \mathrm{~s})$ was $\sim 4 \mathrm{x}$ as long as needed for the commonly used PS Visudyne ${ }^{\circledR}(44 \mathrm{~s})$, when irradiating cell monolayers using a $657 \mathrm{~nm}$ continuous-wave laser at $9.4 \mathrm{~mW} / \mathrm{cm}^{2}$ after $18 \mathrm{~h}$ incubation with $10 \mu \mathrm{M}$ of the drug of interest [89]. In 2013 Ogawa and Kobuke reported the 2PE of water-soluble selfassembled ethynylene-linked conjugated bis-imidazoylporphyrins showing improved two-photon absorption crosssections compared with monomeric porphyrins as well as efficient singlet oxygen generation. Experiments on HeLa cells demonstrated two-photon excited photodynamic activities comparable to hematoporphyrin when irradiating for $5 \mathrm{~min}$ at $780 \mathrm{~nm}$ (2 $\mathrm{mW}$ average power) [100].

Not all approaches towards 2P-PDT to date have been based on the design of novel PSs, and the clinically well characterized PS precursor 5-ALA (5-aminolevulinic acid) has also attracted significant attention as a potential agent 
suitable for 2PE. Madsen et al. used 2PE and fluorescence microscopy of human glioma spheroids to show conversion of 5-ALA to protoporphin IX throughout entire spheroid volumes using an argon-ion pumped dye laser at $635 \mathrm{~nm}$ with a fluence rate of $10 \mathrm{~mW} / \mathrm{cm}^{2}$. They found that the $2 \mathrm{P}$ PDT induced cell killing strongly depends on the light fluence rate used [107]. Beck et al. (2007) reported studies on C6 rat glioma cells incubated with 5-ALA for 4-5 h before excitation at $800 \mathrm{~nm}$ using a fs-pulsed Ti:sapphire laser. Their experiments revealed the successful photodynamic cell killing on cell monolayers when using a mean irradiance of $6.1 \times 10^{10} \mathrm{~W} / \mathrm{cm}^{2}$ [17].

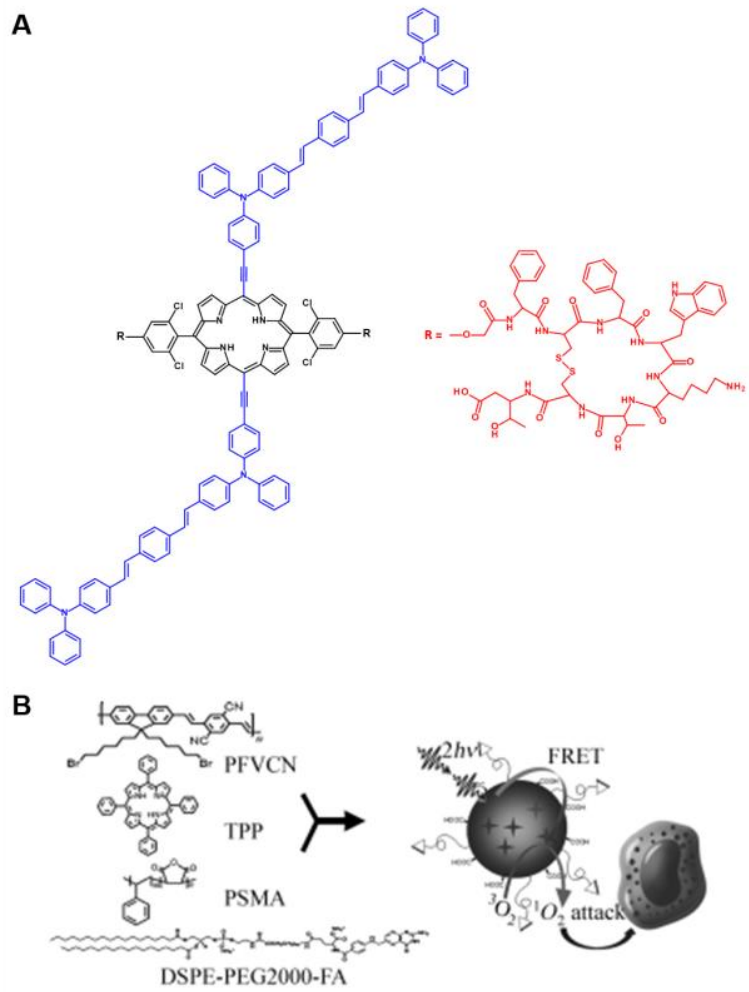

Figure 5 Examples of PSs designed to have high two-photon absorption cross-sections. A Targeted porphyrin-based PS described by Starkey et al. containing the central singlet oxygen generating chromophore (black) to which are attached the conjugated groups (blue) that enhance the two photon cross section, $\sigma_{2}$, to a value of $\sim 2,000 \mathrm{GM}$ at $820 \mathrm{~nm}$ enabling effective application at depths up to $2 \mathrm{~cm}$ in tissues. Also attached are two peptide units ( $R$, red) that target the PS to the tumour [51]. B A nanoparticle-based PS in which a chromophore with high 2PA cross section (PFVCN) transfers excitation energy to the tetraphenylporphyrin (TPP) sensitizer within the particle. In this fashion the efficiency of singlet oxygen generation is increased $\sim 1000 \mathrm{x}$ fold [106].

Approaches towards the development of 2P-PDT for the clinical treatment of age-related macular degeneration (AMD), one of the most common causes for partial blindness of the elderly in the developed world, were reported by different research groups $[17,29,85,108]$. One-photon PDT using Photofrin as PS for the treatment of wet AMD is well established in the clinic. The use of 2P-PDT is believed to enhance the selectivity of the AMD treatment at the abnormal vasculature in the eyes of patients. Two-photon excitation in vitro on vascular endothelial cells using Photofrin ${ }^{\circledR}(\mathrm{GM}<10)$ as PS (excited at $850 \mathrm{~nm}$ ) showed 50 $\%$ cell killing at high laser peak energies of $6300 \mathrm{~J} / \mathrm{cm}^{2}$ [29]. In vivo experiments on highly vascularized chicken chorioallantoic membranes treated with Visudyne ${ }^{\circledR}(689 \mathrm{~nm}$ excitation) confirmed improved localised selectivity of $2 \mathrm{P}$ -
PDT compared with conventional one-photon PDT [108, 109]. In a follow-on study using chicken embryos and mice with implanted tissue windows the same group found that verteporfin 2P-PDT for AMD might provide long-lasting complete blood vessel closure with high selectivity, but preclinical and clinical studies are still required [91]. An example of the success of two-photon activation using verteporfin as PS is shown in Figure 6. Another study reported the localized single blood vessel closure using $2 \mathrm{P}$ PDT in a mouse window chamber model using newly designed conjugated porphyrin dimers as PSs with high efficiency. These PSs are suggested to be particularly powerful if administered in combination with anti-VEGF drugs that prevent the formation of novel abnormal blood vessels [85].

In recent years several research groups proposed the use of nanoparticle-PS systems to improve the targeted drug delivery and the depth of PS activation by upconversion. Gao et al. used so called photodynamic nanoplatforms that combine the ability of tumour detection by MRI (magnetic resonance imaging) and activation by $2 \mathrm{PE}$. The non-toxic nanoplatforms consist of a dye (TMPyP) encapsulated in a neutral, hydrophilic polymer matrix and selectively target cancer cells (C6 rat glioma cells) in vitro [25]. Another approach was proposed using mesoporous silica nanoparticles functionalized with a mannose derivative and containing 6850 units of a covalently encapsulated PS (MSN1-mannose, $118 \mathrm{~nm}$ diameter) for 2P-PDT. The MSN1-mannose nanoparticles were investigated in human breast and colon cancer cell lines, as well as xenograft tumour mice and shown to bind to lectins overexpressed in cancer cells. They have large two-photon absorption crosssections up to $8 \mathrm{MGM}(\sim 1200 \mathrm{GM}$ per individual PS molecule) and therefore might be a promising tool for $2 \mathrm{P}$ PDT cancer therapy [11].
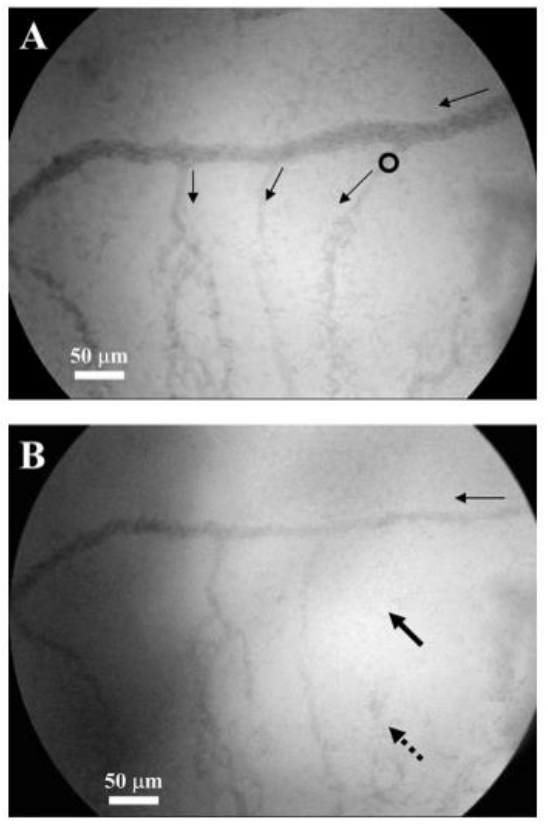

Figure 6 Demonstration of blood vessel closure by two-photon PDT in the in ovo chicken chorioallantoic membrane as a model for AMD treatment. A Before treatment the blood flow in the direction of the thin arrows is observed. B After irradiation at $780 \mathrm{~nm}$ combined with Verteporfin in the area indicated by the circle, blood flow continues in the non-irradiated vessels, but ceases in the occluded vessel indicated by the thick arrows. Adapted from Samkoe et al (2003) [109]. 
A means proposed to achieve more efficient light delivery and improved photosensitization for two-photon PDT was based on polymer nanoparticles $(\sim 50 \mathrm{~nm}$ diameter $)$ conjugated with the PS tetraphenylporphyrin. The twophoton absorption cross-section and singlet oxygen generation efficiency of the PS upon 2PE were found to be increased due to efficient energy transfer from the conjugated polymer nanoparticle shell [110]. In 2012 Idris and co-workers reported the use of mesoporous-silica-coated upconversion fluorescent nanoparticles (UCNs) that convert NIR light penetrating deep into tissues to visible wavelengths thereby activating two PSs (MC540 and ZnPc) carried within the nanoparticles. Tumour growth inhibition in in vivo mouse models using these targeted UCNs was demonstrated upon $980 \mathrm{~nm}$ excitation with an inexpensive continuous wave laser diode [111]. Quantum dots have also been suggested as 2P-PDT agents that act as energy donors for the PSs (acceptors). An example is the use of lipid coated QD-chlorin e6 (Ce6) complexes (QD:Ce6 1:5) that can be excited by one- or two-photons $(1030 \mathrm{~nm}$, free quantum dot $=3325 \mathrm{GM}, \mathrm{Ce} 6=13 \mathrm{GM}$ ) with an energy transfer efficiency of $80 \%$ in solution. [112,113]. These quantum dot complexes have not been evaluated using in vivo systems so far. In another nanoparticle system a dye with high $2 \mathrm{PE}$ cross-section transfers energy by Förster Resonance Energy Transfer within the particle to embedded tetraphenylporphyrin (Figure 5B) resulting in a very large increase in singlet oxygen generation by the PS on excitation at $810 \mathrm{~nm}$ [106].

The targeted delivery of PSs is also of high importance when using 2PE. Celli et al. pointed out the potential of using multiphoton imaging for PDD (Photodynamic Diagnosis or Detection) in combination with PDT making use of the improved light penetration depth and localized fluorescence excitation in tissues in the NIR. This has recently been demonstrated in a nanoparticle construct in which a chromophore with a high two-photon absorption cross-section activates a conjugated PS via energy transfer (FRET) [7]. Starkey et al. (2013) compared the use of octreotate to target SST2 receptors expressed on tumour vessels and EGF receptor (EGFR) targeted peptides conjugated with porphyrin-based PSs for deep tissue 2PPDT treatment on xenograft mouse tumours. It was found that targeting of the SST2 receptors was more effective than that of EGFR as reduction of the tumour vasculature alone inhibited further tumour growth and also that short pulse lengths ( 120 fs) provide the best depth efficiency [114].

In 2008 significant regression of mouse breast and lung cancer xenograft tumours using a tetrapyrrole-based PS designed for $2 \mathrm{PE}$ was reported. Approximately $4 \mathrm{~h}$ after administration the novel 2P-PDT PSs were irradiated at 800 $\mathrm{nm}$ with a femtosecond pulsed Ti:sapphire laser $(1 \mathrm{kHz}$ repetition rate, $600-800 \mathrm{~mW}$ average laser power, $10-20$ $\mathrm{W} / \mathrm{cm}$ average irradiance) leading to tumour regression at a depth of up to $2 \mathrm{~cm}$. Following these experiments the researchers proposed studies in larger animals, in which they expect to be able to excite the PSs effectively at a maximum depth of 5-7 cm [51]. In 2012 Spangler et al, demonstrated the synthesis of so called PDT triads for the treatment of $\mathrm{FaDu}$ Head and Neck SCC (HNSCC) xenograft mouse tumours at depths from $2-5 \mathrm{~cm}$. The PDT triads are comprised of a synthetic porphyrin with a high two-photon absorption cross-section (2000 GM at $840 \mathrm{~nm}$ ), a chromophore for NIR imaging of the triad localization and a small peptide that targets EGF receptors on the cell membrane that are overexpressed in some cancers. It was found that PDT-triad activation using a $150 \mathrm{fs}$ pulsed laser in the NIR for $15-45 \mathrm{~min}(900 \mathrm{~mW})$ led to tumour regression and some complete cures in the mice after 15 - 20 days as well as excellent wound healing [115]. Two years later the same group published the results of an advanced pre-clinical study on EGFR overexpressing HNSCC mouse tumours. The tumours were targeted with two separate dyads, both of which have an EGFR targeting moiety and an imaging agent for image-guided tumour resection or PS molecule respectively. Following the selective dyad uptake the beam from a Ti:sapphire laser was focused to $1 \mathrm{~mm}$ in diameter near the tumour surface $(800 \mathrm{~nm}, 100 \mathrm{fs}$ pulses, $1 \mathrm{kHz}$ repetition rate, $800-900 \mathrm{~mW}$ ) and scanned over the tumour for 20 - 25 min leading to two-photon PS activation and complete regression after 20 days [116]. Additionally in 2015 Zou et al. demonstrated the selective blood-vessel closure and tumour growth inhibition in murine models upon $2 \mathrm{PE}$ at $800 \mathrm{~nm}$. They studied a series of water-soluble bis(arylidene)cycloalkanone PSs modified by polyethylene glycol (PEG). A PS candidate carrying two asymmetric tetraethylene glycol chains performed best and resulted in prolonged survival of the mice, hence indicating the feasibility of using simple molecules to construct novel $2 \mathrm{PE}-$ PDT PS candidates [117].

\subsection{Alternative Strategy for Two-Photon Phototherapy (2P-PDT) without ROS}

We proposed an innovative approach, Type IV PDT, towards the development of a novel type of two-photon phototherapy (2P-PDT) using $E$-combretastatins as virtually non-toxic pro-drugs that can be converted to the highly cytotoxic anticancer drug $Z$-combretastatin by photoisomerization (Figure 7). This direct action of the photo-activated drug enables it to bind to its cellular target and induce cell death. Photoisomerisation of combretastatins represents a different PDT mechanism which unlike Types I and II does not require the presence of oxygen or as for Type III does not involve interaction of the drugs electronic excited triplet state with any other molecule to produce a cytotoxic species.

Combretastatins are natural products that like stilbenes exist in two conformations dependent on the geometry of the substituents relative to the central carbon-carbon double bond. This different geometry leads to different photophysical behaviour, which can be controlled and optimized for PDT. For example, the Z-(cis-) form is non-fluorescent whilst the $E$-(trans-)isomer is fluorescent (Figure 7A). The two isomers also have different biochemical behaviour. The $Z$-isomer binds effectively to tubulin (Figure 7B), therefore inhibiting polymerization to microtubules at nanomolar concentrations and halting cell division which eventually leads to cell death particularly in the rapidly dividing endothelial cells of the tumour vasculature. The $E$-isomer on the other hand does not bind so effectively and as such was found to be considerably less cytotoxic (2-3 orders of magnitude). The anti-vascular effects of $Z$-combretastatins led to phase I-III clinical trials in which a sodium diphosphate derivative of $Z$-combretastatin A4 (Z-CA4) was tested as potential anti-angiogenic anticancer agent. Unfortunately the combretastatin phosphate salt displayed 
severe side effects such as cardiovascular toxicity that prevented the compound from making its way to the clinic $[118,119]$. The $E$-combretastatin pro-drug uptake and distribution in live cells can be monitored by multiphoton FLIM imaging at $625 \mathrm{~nm}$ [120]. It was shown that $E$ combretastatins accumulate rapidly in the cytoplasm of live
CHO, HeLa and HUVEC (human umbilical vein endothelial cells) cells and particularly in lipidic environments such as lipid droplets at concentrations up to two orders of magnitude higher than that of the pro-drug in the surrounding medium $[120,121]$. Mechanistically upon excitation of $E$-combretastatin the molecule is promoted to

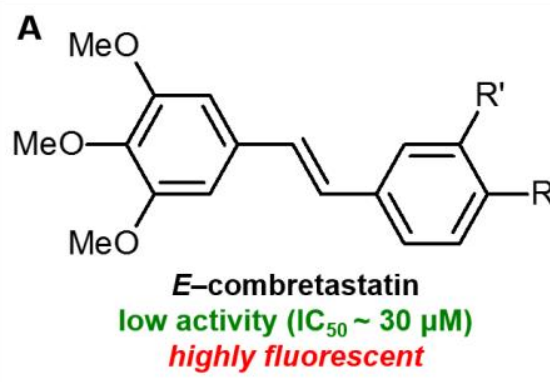

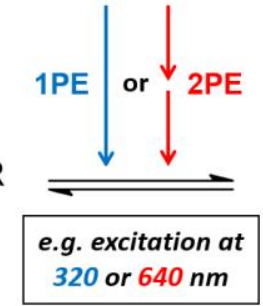

320 or $640 \mathrm{~nm}$<smiles>[R]c1ccc(/C=C\c2cc(OC)c(OC)c(OC)c2)cc1[R]</smiles>

Z-combretastatin

high activity $\left(\mathrm{IC}_{50} \sim 3 \mathrm{nM}\right)$

non-fluorescent

B

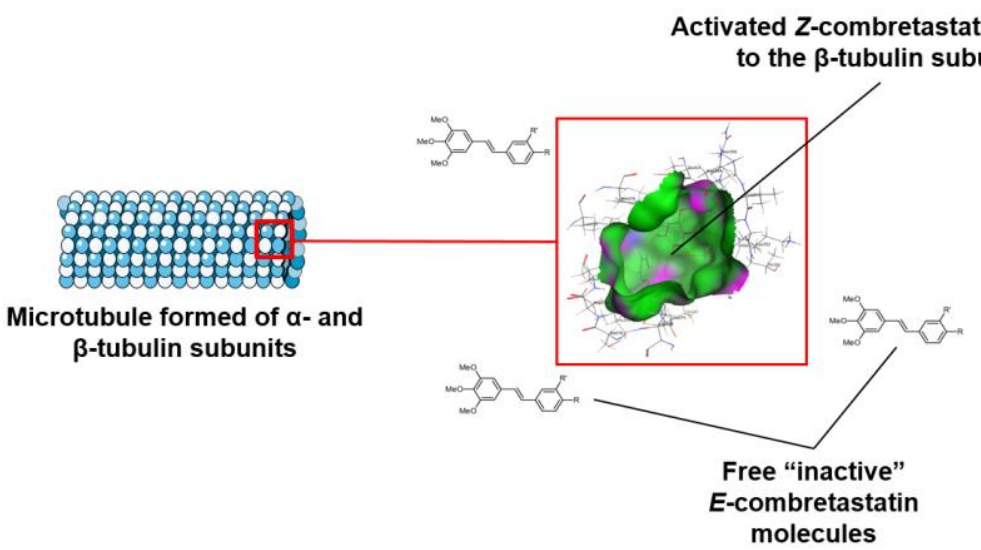

C

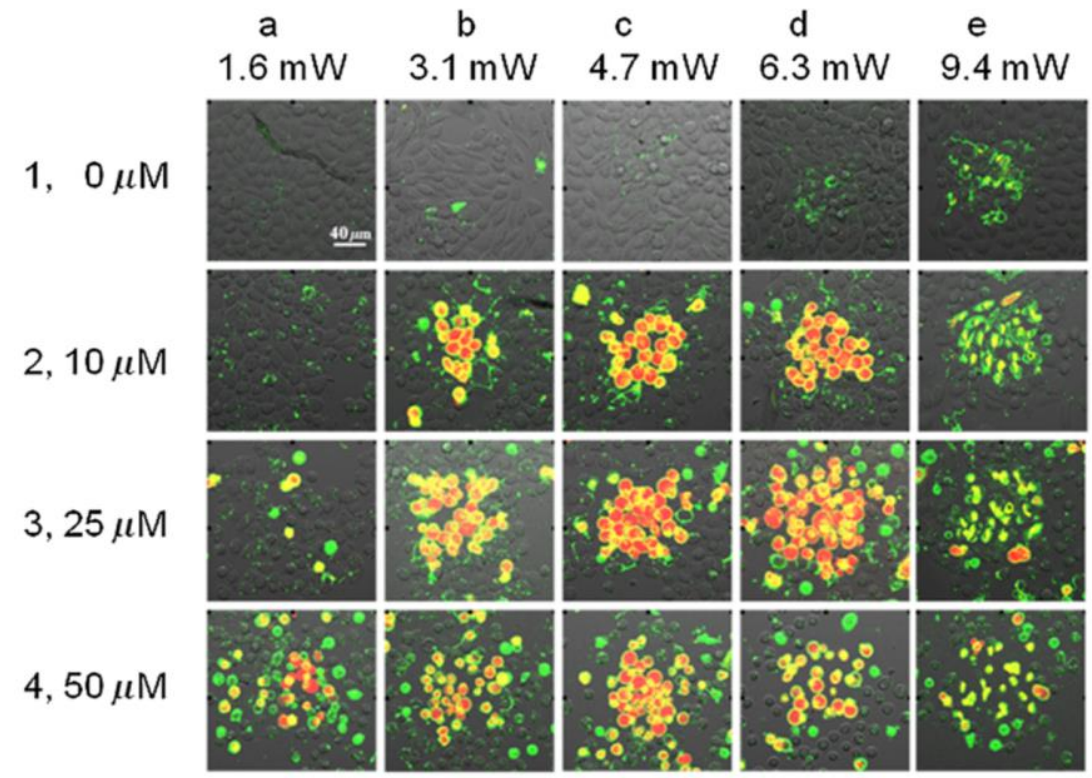

Figure 7 Type IV direct combretastatin activation by two-photon excitation. A Mechanism of one- and two-photon excited reversible E↔Zcombretastatin photoisomerization $\left(\mathrm{R}=-\mathrm{OMe},-\mathrm{CN},-\mathrm{N}\left(\mathrm{CH}_{3}\right)_{2}, \mathrm{R}^{\prime}=-\mathrm{OH},-\mathrm{F},-\mathrm{NH}_{2}\right)$. The fact that the low-binding $E$-isomers are fluorescent permits monitoring of their uptake and localization within target cells prior to photo-activation using fluorescence imaging at low laser powers. B Photoisomerization of $E$ - to $Z$-combretastatin allows binding to its target site in tubulin leading to inhibition of microtubule polymerisation. In the following this causes a halt in cell division and eventually cell death. C Z-Combretastatin A4 induced apoptosis in CHO cell monolayers following photo-activation of $E$-combretastatin A4 (E-CA4) assessed by staining with annexin V AlexaFluor488 conjugate (green) and propidium iodide (red), respectively. $E$-CA4 $(0,10,25$, and $50 \mu \mathrm{M})$ was added to the live cells $2 \mathrm{~h}$ before irradiation of a $100 \times 100 \mu \mathrm{m}$ field for $10 \mathrm{~min}$ at $625 \mathrm{~nm}$ with increasing average laser powers at the sample $(1.6,3.1,4.7,6.3$, and $9.4 \mathrm{~mW})$. Cell killing with micrometre precision was achieved at optimized prodrug concentrations and laser powers (e.g. $2 \& 3$ c or 2d) Figure 7C is adapted from Scherer et al. (2015) [122]. 
its singlet electronic state by one- or two-photon absorption from which it decays by geometric conversion (isomerization) on a sub-nanosecond timescale to its $Z$ isomer. It is a direct pro-drug activation without the need of the formation of a long-lived energy transferring triplet state and furthermore an oxygen-independent process. The photoisomerization process is reversible and depends on the wavelength used for excitation as it is commonly seen for stilbenes [123, 124].

The trans $\rightarrow$ cis photoisomerization of combretastatins by one-photon excitation (with UV light) was first described by Pettit and Singh in 1987, who used this photochemical process to obtain higher yields of the pure and highly active cis-derivative [125].

Two decades later Hadfield and co-workers patented the trans $\rightarrow$ cis photoisomerization of combretastatins by excitation of the compound in a degassed benzene solution using a $400 \mathrm{~W}$ medium pressure mercury lamp. Gas chromatographic analysis demonstrated a rapid one-photon excited isomerization process of CA4 [126]. In taking this concept forward Bisby et al. have characterised the photoisomerization of combretastatins in solution through both one- and $2 \mathrm{PE}$ at 340 and $625 \mathrm{~nm}$, respectively. A key result was the ability to perform highly selective $E$ combretastatin pro-drug activation using a femtosecond pulsed Ti-sapphire laser at $625 \mathrm{~nm}$ within live mammalian cells that induced cell death within $24 \mathrm{~h}$ after irradiation. A major benefit of the two-photon activation of $E$ combretastatins is the high spatial resolution that can be achieved with micrometre precision and the potential to activate the prodrug deep within tissue due to high penetration of red excitation light (Figure 7C). Furthermore, since the isomerization process is oxygen-independent it is predicted that combretastatins might also have high efficiency in hypoxic tumour centres where traditional PSs are completely inefficient [127].

The development of novel combretastatin derivatives with improved two-photon absorption properties whilst maintaining its pharmacological characteristics are underway including the synthesis of new molecules containing cyanosubstituents to improve intramolecular charge transfer properties [128]. Steps towards clinical trials are also a priority with the requirement to identify how effective $2 \mathrm{PE}$ drug activation in tissue can be. Preliminary studies in 3D tissue models has shown promising results achieving combretastatin photoisomerization at up to $1.7 \mathrm{~mm}$ depth in agarose gels [127]. Moving even further into the NIR region to photo-activate the pro-drug may also be beneficial in developing an optimised treatment regime and to this end three-photon excitation (3PE) of $E$-combretastatins at wavelengths $>850 \mathrm{~nm}$ have also been demonstrated as a way to improve the depth limitations of PS activation in tissues $[127,128]$. These studies are the first to demonstrate the photoisomerization of stilbene derivatives for the development of a novel type of 2P-PDT processing the ability to function in a range of cellular environments, including hypoxic regions, such as tumour cores.

Currently 2P-PDT is a new and exciting treatment modality for cancer, and still in its infancy. Agostinis et al. suggested that two-photon PDT may become especially advantageous in the treatment of highly pigmented melanoma or deeper lying tumours [5]. The successful implementation of 2P-PDT in the clinic will depend on the development of inexpensive and reliable pulsed NIR lasers, two-photon endoscopic devices, the design of novel PSs with high two-photon absorption cross sections and good pharmacological properties, ways to target the drug delivery, as well as making the systems easy to use for the clinicians by providing stable treatment protocols $[22,28]$. It has also been proposed that further depth of treatment may be achieved using three-photon excitation of PSs. The 3PE of hematoporphyrin IX (HpD-IX) was demonstrated in DMSO solution with an OPG-laser pumping at $1200 \mathrm{~nm}$ (25 pspulse length) by Cohanoschi et al. (2006) showing useful three-photon absorption cross sections. The results indicate that imaging and PDT at increased depth in tissues may be possible making use of 3PE of PSs within the second "tissue window" between 1100 and $1300 \mathrm{~nm}$ [129].

\subsection{Dosimetry}

Now that a wide range of potential PSs has been developed, and advanced and affordable light sources are available, the demand for precise dosimetry in PDT is increasing, to ensure safe, controlled and reproducible treatment conditions. The fact that the light needs to pass through a range of media including complex optics, water and tissues is a major challenge in dosimetry [15]. A range of other factors contribute to precise dosimetry including the total light dose, the light exposure time, the fluence rate, the irradiation wavelength, drug-to-light interval and the light delivery mode (single, fractionated or metronomic at a low dose over an extended period of time). Also important are the type of PS used, its concentration and localization, as well as the availability of $\mathrm{O}_{2}$ in the tumour which is key to efficient ROS formation (only Type I and II) [5, 15, 28, 69]. Several of these parameters such as the light penetration, tissue oxygen and PSs concentration can fluctuate during the treatment [28]. Ideally clinical dosimetry protocols should be combined with computational modelling (e.g. Monte Carlo modelling) to predict the efficacy of PDT and optimise the treatment parameters based on PS fluorescence and singlet oxygen generation detection [130]. The development of precise PDT dosimetry is a major challenge because of the variety of parameters involved, but has the potential to become a useful tool in the development of patient customized treatments and the optimization of existing protocols.

\subsection{Photodynamic diagnosis/detection (PDD)}

The term photodynamic diagnosis or detection (PDD) describes the detection and monitoring of PS localization, as well as the location, depth and size of tumours and their responses during PDT by using the fluorescence emitted by most PSs. Therefore the PS is irradiated at low laser powers that are sufficient for imaging compared with high powers that are required for PS activation. The relative powers used for imaging or activation are directly related to the PS used. PDD might potentially be beneficial in the diagnosis of early stage cancers and real-time optimization of light delivery parameters could help to improve treatment outcomes [3, 43, 69]. For it to be clinically useful in detecting cancers, adjustment of the irradiation area is necessary and posttreatment PSs need to display sufficient fluorescence which can be difficult because of PS photobleaching caused by the high light dose irradiation during PDT [15, 43]. PDD has been gaining attention by virtue of the number of clinical 
trials showing its usefulness in the detection of bladder carcinoma. Since the late 1990's there have been increasing efforts by numerous research groups to develop fluorescence-based cancer detection using the fluorescence from protoporphyrin IX (PpIX) which accumulates in tumours following the application of 5-ALA. Fluorescence detection using an incoherent light source was found to be a promising tool for the non-invasive endoscopic diagnosis of bladder cancer with high sensitivity and might potentially reduce the need for biopsies [72]. Under operating theatre conditions PDD also provides a real-time surgical indicator on potential cancer zones which aid and guide recognition of areas in need of treatment and may even lead to an automated self-targeting detection and treatment single-shot device. Furthermore the use of photodynamic detection (PDD) following 5-ALA, hexyl-ALA or hypericin administration by transurethral resection of bladder tumours is hoped to lower cancer recurrences [131]. Others suggested to further improve the efficiency of PDD by time-resolved endoscopic detection using the measurement of fluorescence lifetimes on the subcellular level [68]. 5-ALA PDD was not only investigated in bladder cancer, but also proved promising for the intraoperative identification and resection of malignant glioma [132, 133]. The development of interstitial PDT (iPDT) using implanted light sources (e.g. cylindrical light diffusors) for PS excitation in malignant glioma patients is also well underway showing that strong fluorescence intensities reporting high concentrations of PpIX in the tumour before treatment and complete photobleaching following PDT indicate favourable treatment results $[134,135]$. In Europe the fluorescence diagnosis of bladder cancer after injection of hexaminolevulinate solution is clinically approved [136].

The non-invasive fluorescence monitoring of fluorescently labelled epidermal growth factor (EGF) in glioma cells has been suggested as a useful tool to differentiate between EGFR-positive and EGFR-negative tumours noninvasively prior to PDT [137]. PDD was recently evaluated in human malignant glioma biopsies (from 33 patients) that received 5-ALA PDT. Researchers looked for changes in fluorescence (non, weak, strong) to determine cell density and tissue type and were able to differentiate areas of solid tumours and tissues infiltrated by tumour cells, which may be useful during tumour resections [138]. An alternative approach is the monitoring of singlet oxygen luminescence (SOL). Comparison of SOL-based dosimetry with PS (PpIX) photobleaching and reaccumulation following PDT in erythema showed that even though SOL can be a useful parameter to predict the tumour response absolute fluorescence photobleaching is sufficient [139].

\subsection{Targeted photosensitizer delivery}

Recently several research groups reported the development of methods for more effective and targeted PS delivery to specific molecular targets (receptors) expressed by tumour cells or tumour vasculature, e.g. by attaching a PS to monoclonal antibodies or antibody fragments with specificity to certain molecular targets, or encapsulation in a lipoprotein shell. The latter also protects the drugs from enzymatic or macrophagic digestion before reaching its target site. Gold nanoparticles, peptides, proteins such as transferrin, EGF or insulin, low density lipoproteins (LDL), folic acid, carbohydrates, somatostatin and liposomes have also been considered as delivery vehicles for PSs $[5,8,61]$. Some groups suggest that an ideal drug delivery system should ensure the PS delivery into the cell nucleus from where it would have a more detrimental effect compared with PSs that accumulate in the plasma membrane (such as porphyrins), Golgi or mitochondria. One way to achieve the selective nuclear delivery of the PS was reported by Ogura et al. who chemically tethered the PS chlorin to poly-L-lysine $[61,140]$.

Photoimmunoconjugates (PICs) are complexes for the targeted delivery of PSs that consist of a NIR activatable PS (such as benzoporphyrin derivative monoacid A or phthalocyanines) and cancer cell targeting antibodies (e.g. cetuximab) which bind to overexpressed enzymes or receptors in the neoplastic tissue or tumour vasculature $[7$, 141, 142]. Photoimmunotherapy using a NIR absorbing phthalocyanine (IR700) conjugated to monoclonal EGFRbinding antibodies triggered in vivo xenograft tumour shrinkage after irradiation with NIR light in EGFR overexpressing cells. Furthermore PIC fluorescence can be used to monitor the PS localization and accumulation [143]. Benzoporphyrin derivative monoacid-A conjugated to cetuximab, an anti-EGFR antibody, changes the PS localization within EGFR-positive cells from mitochondria to lysosomes. No phototoxicity was observed in EGFRnegative cells [142]. When the same conjugate was additionally incorporated into Preformed Plain Liposomes to form so called photo-immuno-conjugate-associatingliposomes (PICAL) PDT induced cell killing of ovarian cancer cells was further enhanced [144]. The evaluation of PICs in EGFR overexpressing mouse models of A431 squamous cell carcinoma cells in which irradiation leads to fluorescence and ROS generation causing lysosome proteolysis showed cell killing of individual micrometastases [141]. Yano et al. 2011 proposed the addition of a sugar moiety to PSs to improve their targeting towards tumour cells which consume larger amounts of glucose than normal cells (Warburg effect) [3]. The preparation of a nonconjugated tumour targeted NIR imaging agent and PDT PS based on heptamethine dyes (IR-808) which shows efficient light induced cytotoxicity towards cancer cells has also been reported [145].

Hasan et al. and others have found that the cellular expression levels of VEGF and EGFR in prostate, pancreatic and ovarian cancer cells are affected by PDT. These findings indicate that a synergistic treatment approach using PDT in combination with targeted agents might be more effective than the photodynamic treatment alone. Investigations in prostate cancer animal models showed that PDT leads to the accumulation of VEGF, which is believed to have an enhancing effect on tumour growth and metastasis. Using a synergistic approach administrating the VEGF-inhibitor bevacizumab (Avastin ${ }^{\circledR}$ ) encapsulated with benzoporphyrin derivative in animal models of pancreatic cancer showed a significant reduction of lung metastases [6].

In $2014 \mathrm{Hu}$ et al. presented an approach towards the dual targeting of both neoplastic cells and the tumour neovasculature at the same time using newly designed PSfactor VII conjugates that selectively bind to overexpressed tissue factor [8]. An alternative approach for the localized PS delivery is the use of a relatively easy to use portable "fiber 
optic-based sensitizer delivery" device which has recently been successfully tested on ovarian cancer cells. The device has a fluorosilane tip containing the PS pheophorbide $\left(\lambda_{\mathrm{ex}}=\right.$ $669 \mathrm{~nm}$ ) and a hollow fibre that delivers oxygen in vitro to generate ROS [146].

The direct conjugation of PSs to oligonucleotides is another way to improve the targeted drug delivery into tumours. The PS (here chlorin e6) and antisense oligonucleotide (here Bcl-x SSO) polyplexes should ideally co-localize in endocytic vesicles. Irradiation should lead to PS induced ROS generation. The ROS cause disruption of lysosomal or endosomal membranes and hence oligonucleotide and PS release to the cytosol of the target cells, a process called photochemical internalization. This was shown to trigger cancer cell killing by a combination of PDT effects and gene therapy by oligonucleotide mediated oncogene modulation. The use of macromolecule-PS conjugates is believed to be a novel cancer treatment strategy and may be extended to the delivery of siRNA, antisense, single stranded origin (SSO) and miRNA antagomirs [147].

\subsection{Nanoparticles in PDT}

An alternative, more recent approach towards improved PS delivery in PDT, and already mentioned above in the context of metal and metal-coated complexes, is the use of nanoparticles [148]. Other forms of nanoparticles are spiropyran-based systems that shrink to less than half their original size (103 to $49 \mathrm{~nm}$ ) upon irradiation at $365 \mathrm{~nm}$ and therefore show improved penetration, retention in tissues and controlled drug release. When encapsulating drugs such as docetaxel in these nanoparticles they are delivered into tumours and their vasculature more effectively and hence lead to improved treatment efficiency upon irradiation compared with the free drug as shown in mouse sarcoma tumour models [149].

Not only may nanoparticles be employed to potentially improve PS delivery to its target site, but also to improve activation within tissues utilizing "upconversion". A new class of nanomaterials that are relatively non-toxic are lanthanide-doped photon upconverting nanoparticles that transform long-wavelength low energy NIR light into shorter wavelength emission. These lanthanide systems demonstrate deep tissue penetration and are readily imaged deep inside tissues (up to $\sim 3.2 \mathrm{~cm}$ in pork tissue) with low background emission enabling the potential to visualise the light-induced drug release and PDT action [150, 151]. On the downside the absorption cross sections of current upconverting nanoparticles is low and excitation at $980 \mathrm{~nm}$ can lead to water heating effects. This is hoped to be overcome by the development of novel $\mathrm{Nd}-\mathrm{YbEr} / \mathrm{Tm}$ tridopant upconverting nanoparticles that can be excited at $800 \mathrm{~nm}$ [151]. Yang et al. (2014) reported the preparation of silica-coated $\mathrm{NaYF}_{4}: \mathrm{Yb}, \mathrm{Tm} @ \mathrm{NaGdF}_{4}$ upconverting nanoparticles with the PS hypocrellin encapsulated inside silica shells conjugated with folic acid for tumour targeting $\left(\lambda_{\text {ex }}=980\right.$ $\mathrm{nm})$. They also showed that uptake of these upconverting nanoparticles into HeLa and HEK-293 cells and the triggering of cell death following irradiation with NIR light [150].

\subsection{D model systems to study the effectiveness of PDT in vitro}

As mentioned previously a major hurdle for PDT when using $2 \mathrm{PE}$ is to understand the depths of light penetration and distribution within biological tissue. 3D tumour models such as multicellular spheroids that mimic real tissues more realistically than cell monolayers have been recognised as useful tools to characterize light penetration and drug responses. As suggested by several groups they can be particularly useful in studying the effectiveness of PDT [152, 153]. For example high-resolution fluorescence imaging of the clinically approved PS benzoporphyrin-derivative monoacid ring-A (BPD) in 3D models of ovarian cancer using illumination from a fibre optic micro-endoscope has been previously shown and suggested to be such a potentially useful diagnostic tool for studying in combination with PDT in 3D [152]. Furthermore Glidden et al. (2012) investigated the combination of fluorescence imaging to quantify the uptake, localization and photobleaching of BPD with PDT treatment using the same PS under different treatment conditions in 3D pancreatic carcinoma in vitro models [153] as illustrated in Figure 8.

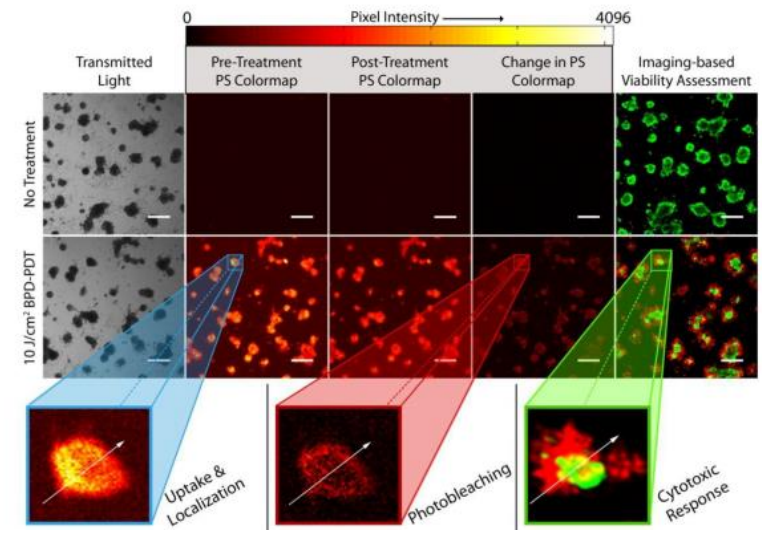

Figure 8 Use of verteporfin (BPD) as PS in a AcPC-1 tumour nodule model. These results demonstrate a) direct fluorescence imaging of PS uptake and localization by confocal microscopy, b) photobleaching of PS as a result of illumination $(690 \mathrm{~nm})$, and c) cytotoxic outcome from a combination of PS and illumination using a live (calcein AM/green fluorescence) - dead (propidium iodide/red fluorescence) assay. (Scale bars $350 \mu \mathrm{m})$. From these combined measurements, it is suggested that parameters for PDT (dose, PS concentration) may be optimized. Illustration adapted from Glidden et al. (2012) [153].

In 2013 Anbil et al. proposed a 3D model system of ovarian cancer spheroids to study the PDT response based on the correlation of live volume (fraction of live cells) and cell viability. A range of PS and light doses were tested demonstrating the most significant effects (reduction in live volume and cell viability) using $0.25 \mu \mathrm{M}$ benzoporphyrin derivative (BPD) irradiated with a 690-nm fibre-coupled diode laser (irradiance of $150 \mathrm{~mW} / \mathrm{cm}^{2}$ ) [154]. Furthermore the real-time imaging of the uptake of $E$-combretastatins in multicellular spheroids $(\sim 400-600 \mu \mathrm{m}$ diameter $)$ as well as the highly selective spatial photo-conversion of combretastatin derivatives in three-dimensional agarose gels at depths up to $1.7 \mathrm{~mm}$ was demonstrated [127]. A key issue is the ability to determine the level of cell death deep within spheroids. It has been suggested to use computational analysis of the fluorescence images obtained from 3D model systems grown in a multi-well format to acquire highthroughput quantitative information on growth inhibition and 
cytotoxicity. Celli et al. recently reported the development of such a platform named qVISTA which is widely accessible to research laboratories with an inverted fluorescence microscope and modestly equipped PC [155].

\subsection{PDT using PSs with antimicrobial effects}

PDT has also been suggested as an alternative to treat bacterial infections particularly under the light of rising antibiotic resistances. Bacterial strains that show resistance to multiple antibiotics are effectively killed by PDT and are less prone to develop resistances [12, 156, 157]. Hamblin and co-workers reported the first proof-of-principle study using PDT to treat bacterially infected wound sites in mice by topically applying a poly-L-lysine and chlorin e6 conjugate to the target site, which was activated with $660 \mathrm{~nm}$ laser light. It was shown that Escherichia coli bacteria responsible for infecting the wounds were rapidly killed by the treatment without harming healthy tissue in the mice [157]. This was followed by studies on other microorganisms such as Staphylococcus aureus and Candida albicans and using additional PSs such as rose Bengal, toluidine blueO and methylene blue. The poly-L-lysine chlorin e6 conjugate reported previously was found to be the most powerful on all microorganisms tested [156]. A range of conditions can potentially be treated using antimicrobial PDT and have been evaluated in preclinical or clinical studies including acne, gastric Helicobacter pylori infections and brain abscesses using acridines or hypericin as PSs [12].

\section{FUTURE OUTLOOK \& CONCLUSION - CHALLENGES AND FUTURE DIRECTIONS IN PDT}

Since the 1970s, when PDT was first evaluated in clinical trials for cancer treatment using porphyrin derivatives as PSs, there has been a continuously increasing amount of research in the field. Hundreds of new PSs have been designed [43] with a more recent focus on targeted drug delivery by a range of groups. Gradually better and more cost-effective light sources are being developed and becoming commercially available (including portable pulsed diode lasers). The efficiency of PDT using a wide range of PSs has been evaluated extensively in vitro and in vivo, as well as in early stage clinical trials particularly in advanced cancers. Due to a lack of extensive phase III clinical studies PDT is still regarded as a niche option for the palliative care of very advanced cancers. Researchers in the field from the UK, USA, Denmark, South Africa and Germany feel that the field of PDT is narrowing down, particularly on the clinical aspect due to a lack of available funding for expensive advanced clinical studies. Nonetheless, the amount of fundamental research concerned with improving the tools for PDT such as PSs, drug delivery, light sources and dosimetry shows that the field is still very active. Currently the most promising clinical application seems to lie in the treatment of AMD and antibacterial PDT rather than cancer.

The use of 2PE for the activation of PSs has been shown to give an advantage over 1PE for PDT at improved depths in tissues with precisely localized PS activation and may be more effective in hypoxic tumour areas. This may also be particularly useful in the targeted PS activation at the vasculature. The company SensoPath Technologies, Inc. reports that they are moving rapidly into the clinic using targeted image-guided two-photon PDT for the treatment of HNSCC in dogs and cats. There are also plans to commence phase I and II human trials in the near future and to bring two-photon PDT to the veterinary market using next generation PDT agents.

The multifaceted nature of cancer certainly requires a variety of treatments to be made available. Ongoing technological, fundamental and clinical research fully supports a viable route towards establishing PDT as a mainstream cancer treatment modality or at the very least a treatment modality that can be used in combination to other cancer therapies. For PDT to become widely accepted, precise and reliable dosimetry of the light delivery, as well as the PS and oxygen concentration at the tumour site, are essential. The development of complete, inexpensive and efficient treatment packages for clinicians that include the light source, PS and a simple treatment protocol is highly desirable.

\section{CONFLICT OF INTEREST}

RHB, SWB and KMS are authors of a patent on the "Multi-photon isomerisation of combretastatins and their use in therapy (WO 2013021208 A2).

\section{ACKNOWLEDGEMENTS}

Author contributions: KMS wrote the manuscript and prepared Figures 1, 2, 3 and 7. RHB prepared Figures 4 and 5 and sought permission for reprints of Figures 6 and 8 . RHB, SWB and AWP critically read, drafted and edited the manuscript and figures. We acknowledge the University of Salford and the STFC Futures Programme for funding.

\section{REFERENCES}

[1] Cancer Research UK. What is cancer? http://www.cancerresearchuk.org/about-cancer/what-is-cancer (Accessed June 02, 2015).

[2] Inui, T.; Kuchiike, D.; Kubo, K.; Mette, M.; Uto, Y.; Hori, H.; Sakamoto, N. Clinical experience of integrative cancer immunotherapy with GcMAF. Anticancer Res., 2013, 33(7), 2917-2919.

[3] Yano, S.; Hirohara, S.; Obata, M.; Hagiya, Y.; Ogura, S.-I.; Ikeda, A.; Kataoka, H.; Tanaka, M.; Joh, T. Current states and future views in photodynamic therapy. J. Photochem. Photobiol. C Photochem. Rev., 2011, 12 (1), 46-67.

[4] Lane, N. New light on medicine. Sci. Am., 2003, 80-87.

[5] Agostinis, P.; Berg, K.; Cengel, K.A.; Foster, T.H.; Girotti, A.W.; Gollnick, S.O.; Hahn, S.M.; Hamblin, M.R.; Juzeniene, A.; Kessel, D.; Korbelik, M.; Moan, J.; Mroz, P.; Nowis, D.; Piette, J.; Wilson, B.C.; Golab, J. Photodynamic therapy of cancer: An update. CA Cancer J.Clin., 2011, 61(4), 250-281.

[6] Hasan, T. Using cellular mechanisms to develop effective combinations of photodynamic therapy and targeted therapies. J. Natl. Compr. Cancer Netw., 2012, 10, 23-26.

[7] Celli, J.P.; Spring, B.Q.; Rizvi, I.; Evans, C.L.; Samkoe, K.S.; Verma, S.; Pogue, B.W.; Hasan, T. Imaging and photodynamic therapy: mechanisms, monitoring, and optimization. Chem. Rev., 2010, 110(5), 2795-2838.

[8] Hu, Z.; Oleinick, N.; Hamblin, M.R. Photodynamic Therapy as an Emerging Treatment Modality for Cancer and Non-Cancer Diseases. $J$. Anal. Bioanal. Tech., 2014, S1(e001), 1-3.

[9] Spikes, J.D. Phthalocyanines as photosensitizers in biological systems and for the photodynamic therapy of tumours. Photochem. Photobiol., 1986, 43, 691-699.

[10] Dougherty, T.J.; Gomer, C.J.; Henderson, B.W.; Jori, G.; Kessel, D.; Korbelik, M.; Moan, J.; Peng, Q. Photodynamic therapy. JNCI J. Natl. Cancer Inst., 1998, 90(12), 889-905. 
[11] Gary-Bobo, M.; Mir, Y.; Rouxel, C.; Brevet, D.; Basile, I.; Maynadier, M.; Vaillant, O.; Mongin, O.; Blanchard-Desce, M.; Morère, A.; Garcia, M.; Durand, J.-O.; Raehm, L. Mannose-functionalized mesoporous silica nanoparticles for efficient two-photon photodynamic therapy of solid tumors. Angew. Chem. Int. Ed. Engl., 2011, 50(48), 11425-11429.

[12] Hamblin, M.R.; Hasan, T. Photodynamic therapy: a new antimicrobial approach to infectious disease? Photochem. Photobiol. Sci., 2004, 3(5), 436-450.

[13] Patrick, G.L. An Introduction to Medicinal Chemistry, Oxford University Press, USA, 2009.

[14] Cancer Research UK. Photodynamic therapy. http://www.cancerresearchuk.org/about-cancer/cancers-ingeneral/treatment/other/photodynamic-therapy-pdt (Accessed June 02, 2015).

[15] Plaetzer, K.; Krammer, B.; Berlanda, J.; Berr, F.; Kiesslich, T. Photophysics and photochemistry of photodynamic therapy: fundamental aspects. Lasers Med. Sci., 2009, 24(2), 259-268.

[16] Altshuler, G.B.; Yaroslavsky, I. Absorption characteristics of tissues as a basis for the optimal wavelength choice in photodermatology. Palomar Med. Technol. Burlingt., 2004, 1-4.

[17] Beck, T.J.; Burkanas, M.; Bagdonas, S.; Krivickiene, Z.; Beyer, W.; Sroka, R.; Baumgartner, R.; Rotomskis, R. Two-photon photodynamic therapy of C6 cells by means of 5-aminolevulinic acid induced protoporphyrin IX. J. Photochem. Photobiol. B Biol., 2007, 87(3), 174182.

[18] Anand, S.; Wilson, C.; Hasan, T.; Maytin, E. V Vitamin D3 enhances the apoptotic response of epithelial tumors to aminolevulinate-based photodynamic therapy. Cancer Res., 2011, 71(18), 6040-6050.

[19] Chang, R. Physical Chemistry for the Chemical and Biological Sciences, University Science Books, 2000.

[20] NHS. Photodynamic Therapy (PDT). http://www.nhs.uk/conditions/photodynamic-therapy-NGPDTsonodynamic-therapy/Pages/Introduction.aspx (Accessed June 02, 2015).

[21] Photodynamic therapy for cancer. National Cancer Institute. http://www.cancer.gov/cancertopics/factsheet/Therapy/photodynamic (Accessed June 02, 2015).

[22] Thurston, D.E. Chemistry and pharmacology of anticancer drugs, $1^{\text {st }}$ ed.; Boca Raton: CRC Press, Taylor \& Francis Group, 2007.

[23] Castano, A.P.; Demidova, T.N.; Hamblin, M.R. Mechanisms in photodynamic therapy: part two - cellular signaling, cell metabolism and modes of cell death. Photodiagnosis Photodyn. Ther., 2005, 2(1), $1-23$.

[24] Foye, W.O.; Lemke, T.L.; Williams, D.A. Principles of Medicinal Chemistry, Williams \& Wilkins, 1995.

[25] Gao, D.; Agayan, R.R.; Xu, H.; Philbert, M.A.; Kopelman, R. Nanoparticles for two-photon photodynamic therapy in living cells. Nano Lett., 2006, 6, 2383-2386.

[26] Mroz, P.; Yaroslavsky, A.; Kharkwal, G.B.; Hamblin, M.R. Cell death pathways in photodynamic therapy of cancer. Cancers (Basel)., 2011, $3(2), 2516-2539$.

[27] Photodynamic Therapy (PDT). http://www.nhs.uk/conditions/photodynamic-therapy-NGPDTsonodynamic-therapy/Pages/Introduction.aspx. (Accessed June 2, 2015).

[28] Wilson, B.C.; Patterson, M.S. The physics, biophysics and technology of photodynamic therapy. Phys. Med. Biol., 2008, 53(9), 61-109.

[29] Karotki, A.; Khurana, M.; Lepock, J.R.; Wilson, B.C. Simultaneous two-photon excitation of Photofrin $®$ in relation to photodynamic therapy. Photochem. Photobiol., 2006, 82(2), 43-452.

[30] Quirk, B.J.; Brandal, G.; Donlon, S.; Carlos, J.; Mang, T.S.; Foy, A.B.; Lew, S.M.; Girotti, A.W.; Jogal, S.; Laviolette, P.S.; Connelly, J.M.; Whelan, H.T. Photodynamic therapy (PDT) for malignant brain tumors
- Where do we stand? Photodiagnosis Photodyn. Ther., 2015, 12(3), 530-544.

[31] Hönigsmann, H. History of phototherapy in dermatology. Photochem. Photobiol. Sci., 2013, 12(1), 16-21.

[32] Mitton, D.; Ackroyd, M.D. A brief overview of photodynamic therapy in Europe. Photodiagnosis Photodyn. Ther., 2008, 5, 103-111.

[33] Lipson, R.L. The photodynamic properties of a particular hematoporphyrin derivative. Arch. Dermatol., 1960, 82(4), 508.

[34] Lipson, R.L.; Baldes, E.J.; Olsen, A.M. The use of a derivative of hematoporhyrin in tumor detection. J. Natl. Cancer Inst., 1961, 26, 111 .

[35] Lipson, R.L.; Baldes, E.J.; Olsen, A.M. Further evaluation of the use of hematoporphyrin derivative as a new aid for the endoscopic detection of malignant disease. Dis. Chest, 1964, 46, 676-679.

[36] Sano, S.; Rimington, C. Excretion of various porphyrins and their corresponding porphyrinogens by rabbits after intravenous injection. Biochem. J., 1963, 86(1957), 203-212.

[37] Pimstone, N.R. Utility of porphyrins and light in the diagnosis and treatment of malignancy. Hepatology, 1985, 5(2), 338-340.

[38] Dougherty, T.J.; Kaufman, J.E.; Goldfarb, A.; Weishaupt, K.R.; Boyle, D.; Mittleman, A. Photoradiation therapy for the treatment of malignant tumors. Cancer Res., 1978, 38, 2628-2635.

[39] Dolmans, D.E.J.G.J.; Fukumura, D.; Jain, R.K. Photodynamic therapy for cancer. Nat. Rev. Cancer, 2003, 3, 380 - 387.

[40] Gál, D.; Kriska, T.; Shutova, T.; Németh, A. Additional approach to PDT : Type III . mechanism and the role of native free radicals. Proc. SPIE, 2001, 4248, $169-178$.

[41] Kriska, T.; Jakus, J.; Keszler, A.; Vanyur, R.; Németh, A.; Gál, D. Type III photosensitization: attempt for quantification and a way to new sensitizers. SPIE, 1998, 3563, $11-17$.

[42] Yoon, I.; Li, J.Z.; Shim, Y.K. Advance in photosensitizers and light delivery for photodynamic therapy. Clin. Endosc., 2013, 46, 7 - 23.

[43] Castano, A.P.; Demidova, T.N.; Hamblin, M.R. Mechanisms in photodynamic therapy: part one-photosensitizers, photochemistry and cellular localization. Photodiagnosis Photodyn. Ther., 2004, 1(4), 279293.

[44] Phillips, D. Photodynamic therapy. Sci. Rev. 2000 Ltd., 1994, 77, 295 316.

[45] Wilson, B.C.; Patterson, M.S. The physics of photodynamic therapy. Phys. Med. Biol., 1986, 31(4), 327-360.

[46] Flock, S.T.; Wilson, B.C.; Patterson, M.S. Total attenuation coefficients and scattering phase functions of tissues and phantom materials at 633 nm. Med. Phys., 1987, 14(5), 835-881.

[47] Flock, S.T.; Patterson, M.S.; Wilson, B.C.; Wyman, D.R. Monte Carlo modeling of light propagation in highly scattering tissues. I. Model predictions and comparison with diffusion theory. IEEE Trans. Biomed. Eng., 1989, 36(12), 1162-1168.

[48] Patterson, M.S.; Wilson, B.C.; Wyman, D.R. The propagation of optical radiation in tissue I. Models of radiation transport and their application. Lasers Med. Sci., 1991, 6(2), 155-168.

[49] Peters, V.G.; Wyman, D.R.; Patterson, M.S.; Frank, G.L. Optical properties of normal and diseased human breast tissues in the visible and near infrared. Phys. Med. Biol., 1990, 35(9), 1317-1334.

[50] Karotki, A.; Kruk, M.; Drobizhev, M.A.; Rebane, A.K.; Nickel, E.; Spangler, C.W. Efficient singlet oxygen generation upon two-photon excitation of new porphyrin with enhanced nonlinear absorption. IEEE J. Sel. Top. Quantum Electron., 2001, 7(6), 971-975.

[51] Starkey, J.R.; Rebane, A.K.; Drobizhev, M.A.; Meng, F.; Gong, A.; Elliot, A.; McInnerney, K.; Spangler, C.W. New two-photon activated photodynamic therapy sensitizers induce xenograft tumor regressions after near-IR laser treatment through the body of the host mouse. Clin. Cancer Res., 2008, 14, 6564-6573. 
[52] Scherer, K.M. Two-Photon Microscopy of E-Combretastatin Uptake and Activation in Live Mammalian Cells. PhD Thesis, University of Salford: Salford, November 2012.

[53] Weissleder, R.; Ntziachristos, V. Shedding light onto live molecular targets. Nat. Med., 2003, 9, 123-128.

[54] Castano, A.P.; Mroz, P.; Hamblin, M.R. Photodynamic therapy and anti-tumour immunity. Nat. Rev. Cancer, 2006, 6(7), 535-545.

[55] Scully, A.D.; Macrobert, A.J.; Botchway, S.W.; O’Neill, P.; Parker, A.W.; Ostler, R.B.; Phillips, D. Development of a laser-based fluorescence microscope with subnanosecond time resolution. $J$. Fluoresc., 1996, 6(2), 119-125.

[56] Kammerer, R.; Buchner, A.; Palluch, P.; Pongratz, T.; Oboukhovskij, K.; Beyer, W.; Johansson, A.; Stepp, H.; Baumgartner, R.; Zimmermann, W. Induction of immune mediators in glioma and prostate cancer cells by non-lethal photodynamic therapy. PLoS One, 2011, 6(6), e21834.

[57] Dahle, J.; Bagdonas, S.; Kaalhus, O.; Olsen, G.; Steen, H.B.; Moan, J. The bystander effect in photodynamic inactivation of cells. Biochim. Biophys. Acta, 2000, 1475(3), 273-280.

[58] Blázquez-Castro, A.; Breitenbach, T.; Ogilby, P.R. Singlet oxygen and ROS in a new light: low-dose subcellular photodynamic treatment enhances proliferation at the single cell level. Photochem. Photobiol. Sci., 2014, 13(9), 1235-1240.

[59] Phillips, D. The photochemistry of sensitisers for photodynamic therapy. Pure Appl. Chem., 1995, 67(1), 117-126.

[60] Mroz, P.; Tegos, G.P.; Gali, H.; Wharton, T.; Sarna, T.; Hamblin, M.R. Photodynamic therapy with fullerenes. Photochem. Photobiol. Sci., 2007, 6(11), 1139-1149.

[61] Savage, L. PDT for cancer depends on improved photosensitizers. Biophotonics, 2012, 1-4.

[62] Babbar, A.K.; Singh, A.K.; Goel, H.C.; Chauhan, U.P.; Sharma, R.K. Evaluation of $(99 \mathrm{~m}) \mathrm{Tc}-$ labeled photosan-3, a hematoporphyrin derivative, as a potential radiopharmaceutical for tumor scintigraphy. Nucl. Med. Biol., 2000, 27(4), 419-426.

[63] Maisch, T.; Wagner, J.; Papastamou, V.; Nerl, H.-J.; Hiller, K.-A.; Szeimies, R.-M.; Schmalz, G. Combination of 10\% EDTA, Photosan, and a blue light hand-held photopolymerizer to inactivate leading oral bacteria in dentistry in vitro. J. Appl. Microbiol., 2009, 107(5), 15691578.

[64] Ferreira, I.; Rahal, S.C.; Rocha, N.S.; Gouveia, A.H.; Corrêa, T.P.; Carvalho, Y.K.; Bagnato, V.S. Hematoporphyrin-based photodynamic therapy for cutaneous squamous cell carcinoma in cats. Vet. Dermatol., 2009, 20(3), 174-8.

[65] Ribeiro, A.P.D.; Pavarina, A.C.; Trindade, F.Z.; Inada, N.M.; Bagnato, V.S.; de Souza Costa, C.A. Photodynamic therapy associating Photogem and blue LED on L929 and MDPC-23 cell culture. Cell Biol. Int., 2010, 34(4), 343-51.

[66] Allison, R.R.; Downie, G.H.; Cuenca, R.; Hu, X.H.; Childs, C.J.H.; Sibata, C.H. Photosensitizers in clinical PDT. Photodiagnosis Photodyn. Ther., 2004, 1(1), 27-42.

[67] Copley, L.; van der Watt, P.; Wirtz, K.W.; Parker, M.I.; Leaner, V.D. Photolon, a chlorin e6 derivative, triggers ROS production and lightdependent cell death via necrosis. Int. J. Biochem. Cell Biol., 2008, $40(2), 227-35$.

[68] Rück, A.; Dolp, F.; Hülshoff, C.; Hauser, C.; Scalfi-Happ, C. Fluorescence lifetime imaging in PDT. An overview. Med. Laser Appl., 2005, 20(2), 125-129.

[69] Anand, S.; Ortel, B.J.; Pereira, S.P.; Hasan, T.; Maytin, E.V Biomodulatory approaches to photodynamic therapy for solid tumors. Cancer Lett., 2012, 326(1), 8-16.

[70] Kennedy, J.C.; Pottier, R.H.; Pross, D.C. Photodynamic therapy with endogenous protoporphyrin IX: basic principles and present clinical experience. J. Photochem. Photobiol. B., 1990, 6(1-2), 143-148.
[71] Kriegmair, M.; Baumgartner, R.; Lumper, W.; Waidelich, R.; Hofstetter, A. Early clinical experience with 5-aminolevulinic acid for the photodynamic therapy of superficial bladder cancer. Br. J. Urol., 1996, 77(5), 667-671.

[72] Kriegmair, M.; Zaak, D.; Knüchel, R.; Baumgartner, R.; Hofstetter, A. 5-Aminolevulinic acid-induced fluorescence endoscopy for the detection of lower urinary tract tumors. Urol. Int., 1999, 63(1), 27-31.

[73] Waidelich, R.; Beyer, W.; Knüchel, R.; Stepp, H.; Baumgartner, R.; Schröder, J.; Hofstetter, A.; Kriegmair, M. Whole bladder photodynamic therapy with 5 -aminolevulinic acid using a white light source. Urology, 2003, 61(2), 332-337.

[74] Bagdonas, S.; Kirdaite, G.; Streckyte, G.; Graziene, V.; Leonaviciene, L.; Bradunaite, R.; Venalis, A.; Rotomskis, R. Spectroscopic study of ALA-induced endogenous porphyrins in arthritic knee tissues: targeting rheumatoid arthritis PDT. Photochem. Photobiol. Sci., 2005, 4(7), 497502 .

[75] Stepp, H.; Beck, T.J.; Pongratz, T.; Meinel, T.; Kreth, F.-W.; Tonn, J.C.; Stummer, W. ALA and malignant glioma: fluorescence-guided resection and photodynamic treatment. J. Environ. Pathol. Toxicol. Oncol., 2007, 26(2), 157-164.

[76] Kanick, S.C.; Davis, S.C.; Zhao, Y.; Hasan, T.; Maytin, E. V; Pogue, B.W.; Chapman, M.S. Dual-channel red/blue fluorescence dosimetry with broadband reflectance spectroscopic correction measures protoporphyrin IX production during photodynamic therapy of actinic keratosis. J. Biomed. Opt., 2014, 19(7), 075002-1-075002-15.

[77] Philchenkov, A.A.; Shishko, E.D.; Zavelevich, M.P.; Kuiava, L.M.; Miura, K.; Blokhin, D.Y.; Shton, I.O.; Gamaleia, N.F. Photodynamic responsiveness of human leukemia Jurkat/A4 cells with multidrug resistant phenotype. Exp. Oncol., 2014, 36(4), 241-245.

[78] Bader, M.J.; Stepp, H.; Beyer, W.; Pongratz, T.; Sroka, R.; Kriegmair, M.; Zaak, D.; Welschof, M.; Tilki, D.; Stief, C.G.; Waidelich, R. Photodynamic therapy of bladder cancer - a phase I study using hexaminolevulinate (HAL). Urol. Oncol. Semin. Orig. Investig., 2013, 31(7), 1178-1183.

[79] Dimofte, A.; Zhu, T.C.; Hahn, S.M.; Lustig, R.A. In vivo light dosimetry for motexafin lutetium-mediated PDT of recurrent breast cancer. Lasers Surg. Med., 2002, 31(5), 305-312.

[80] Stripp, D.C.H.; Mick, R.; Zhu, T.C.; Whittington, R.; Smith, D.; Dimofte, A.; Finlay, J.C.; Miles, J.; Busch, T.M.; Shin, D.; Kachur, A.; Tochner, Z.A.; Malkowicz, S.B.; Glatstein, E.; Hahn, S.M. Phase I Trial of Motexafin Lutetium-Mediated Interstitial Photodynamic Therapy in Patients with Locally Recurrent Prostate Cancer. Proc. SPIE, 2004, $5315,88-99$.

[81] Patel, H.; Mick, R.; Finlay, J.; Zhu, T.C.; Rickter, E.; Cengel, K.A.; Malkowicz, S.B.; Hahn, S.M.; Busch, T.M. Motexafin lutetiumphotodynamic therapy of prostate cancer: short- and long-term effects on prostate-specific antigen. Clin. Cancer Res., 2008, 14(15), 48694876.

[82] Agostinis, P.; Vantieghem, A.; Merlevede, W.; de Witte, P.A.M. Hypericin in cancer treatment: More light on the way. Int. J. Biochem. Cell Biol., 2002, 34(3), 221-241.

[83] Head, C.S.; Luu, Q.; Sercarz, J.; Saxton, R. Photodynamic therapy and tumor imaging of hypericin-treated squamous cell carcinoma. World $J$. Surg. Oncol., 2006, 4(87), 1-10.

[84] Garg, A.D.; Bose, M.; Ahmed, M.I.; Bonass, W.A.; Wood, S.R. In vitro studies on erythrosine-based photodynamic therapy of malignant and pre-malignant oral epithelial cells. PLoS One, 2012, 7(4), e34475.

[85] Khurana, M. Two-photon excitation photodynamic therapy for localized blood vessel targeting. $\mathrm{PhD}$ Thesis, University of Toronto: Toronto, October 2010.

[86] Feng, X.; Zhang, Y.; Wang, P.; Liu, Q.; Wang, X. Energy metabolism targeted drugs synergize with photodynamic therapy to potentiate breast cancer cell death. Photochem. Photobiol. Sci., 2014, 13(12), 17931803. 
[87] Fisher, W.G.; Partridge, W.P.; Dees, C.; Wachter, E.A. Simultaneous two-photon activation of type-I photodynamic therapy agents. Photochem. Photobiol., 1997, 66(2), 141-155.

[88] Göbel, W.; Brucker, D.; Kienast, Y.; Johansson, A.; Kniebühler, G.; Rühm, A.; Eigenbrod, S.; Fischer, S.; Goetz, M.; Kreth, F.-W.; Ehrhardt, A.; Stepp, H.; Irion, K.-M.; Herms, J. Optical needle endoscope for safe and precise stereotactically guided biopsy sampling in neurosurgery. Opt. Express, 2012, 20(24), 26117-26126.

[89] Dahlstedt, E.; Collins, H.A.; Balaz, M.; Kuimova, M.K.; Khurana, M.; Wilson, B.C.; Phillips, D.; Anderson, H.L. One- and two-photon activated phototoxicity of conjugated porphyrin dimers with high twophoton absorption cross sections. Org. Biomol. Chem., 2009, 7(5), 897904.

[90] Denk, W.; Strickler, J.P.; Webb, W.W. Two-photon laser scanning microscopy. U.S. Patent US5034613A, July 23, 1991.

[91] Probodh, I.; Cramb, D. In: Age-Related Macular Degeneration; GuiShuang Ying, Ed.; Intech, 2012; Chapter 11, pp. 213-226.

[92] Göppert-Mayer, M. Über Elementarakte mit zwei Quantesprüngen. Ann. Phys., 1931, 401(3), 273-294.

[93] Bodaness, R.S.; King, D.S. The two-photon laser-induced fluorescence of the tumor-localizing photosensitizer hematoporphyrin derivative. $J$. Biol. Chem., 1986, 261(26), 12098-12101.

[94] Mir, Y.; van Lier, J.E.; Allard, J.-F.; Morris, D.; Houde, D. Two-photon absorption cross section of excited phthalocyanines by a femtosecond Ti-sapphire laser. Photochem. Photobiol. Sci., 2009, 8, 391-395.

[95] Mathai, S.; Bird, D.K.; Stylli, S.S.; Smith, T.A; Ghiggino, K.P. Twophoton absorption cross-sections and time-resolved fluorescence imaging using porphyrin photosensitisers. Photochem. Photobiol. Sci., 2007, 6(9), 1019-1026.

[96] Andreoni, A.; Cubeddu, R.; De Silvestri, S.; Laporta, P.; Svelto, O. Two-step laser activation of hematoporphyrin derivative. Chem. Phys. Lett., 1982, 88(1), 37-39.

[97] Bodaness, R.S.; King, S. The two-photon induced fluorescence of the tumor localizing photosensitizer hematoporphyrin derivative via 1064 $\mathrm{nm}$ photons from a $20 \mathrm{~ns}$ Q-switched ND:YAG laser. Biochem. Biophys. Res. Commun., 1985, 126(1), 346-351.

[98] Inaba, H.; Shimamoto, M.; Mashiko, S.; Sato, S.; Kuwahara, T.; Taguchi, Y.; Kasai, M. In: LASER - Optoelectronis in Medicine; Wilhelm Waidelich \& Raphaela Waidelich, Ed.; Springer Berlin, Heidelberg, Part I, 1986, pp. 66-69.

[99] Mashiko, S.; Inaba, H.; Sato, S.; Taguchi, Y.; Kimura, S. In: LASER Optoelectronis in Medicine; Wilhelm Waidelich \& Raphaela Waidelich, Ed.; Springer Berlin, Heidelberg, 1988, pp. 633-636.

[100] Ogawa, K.; Kobuke, Y. Two-photon photodynamic therapy by watersoluble self-assembled conjugated porphyrins. Biomed Res. Int., 2013, 2013, 1-11.

[101]Pawlicki, M.; Collins, H.A.; Denning, R.G.; Anderson, H.L. Twophoton absorption and the design of two-photon dyes. Angew. Chem. Int. Ed. Engl., 2009, 48(18), 3244-3266.

[102]Bhawalkar, J.D.; Kumar, N.D.; Zhao, C.F.; Prasad, P.N. Two-photon photodynamic therapy. J. Clin. Laser Med. Surg., 1997, 15(5), 201204.

[103] Gallavardin, T.; Maurin, M.; Marotte, S.; Simon, T.; Gabudean, A.-M.; Bretonnière, Y.; Lindgren, M.; Lerouge, F.; Baldeck, P.L.; Stéphan, O.; Leverrier, Y.; Marvel, J.; Parola, S.; Maury, O.; Andraud, C. Photodynamic therapy and two-photon bio-imaging applications of hydrophobic chromophores through amphiphilic polymer delivery. Photochem. Photobiol. Sci., 2011, 10(7), 1216-1225.

[104]Collins, H.A.; Khurana, M.; Moriyama, E.H.; Mariampillai, A.; Dahlstedt, E.; Balaz, M.; Kuimova, M.K.; Drobizhev, M.; Yang, V.X.D.; Phillips, D.; Rebane, A.; Wilson, B.C.; Anderson, H.L. Bloodvessel closure using photosensitizers engineered for two-photon excitation. Nat. Photonics, 2008, 2, 420-424.
[105]Kuimova, M.K.; Collins, H.A.; Balaz, M.; Dahlstedt, E.; Levitt, J.A.; Sergent, N.; Suhling, K.; Drobizhev, M.; Makarov, N.S.; Rebane, A.; Anderson, H.L.; Phillips, D. Photophysical properties and intracellular imaging of water-soluble porphyrin dimers for two-photon excited photodynamic therapy. Org. Biomol. Chem., 2009, 7, 889-896.

[106]Shen, X.; Li, S.; Li, L.; Yao, S.Q.; Xu, Q.-H. Highly efficient, conjugated-polymer-based nano-photosensitizers for selectively targeted two-photon photodynamic therapy and imaging of cancer cells. Chemistry, 2015, 21, $2214-2221$.

[107]Madsen, S.J.; Sun, C.; Tromberg, B.J.; Wallace, V.P.; Hirschberg, H. Photodynamic therapy of human glioma spheroids using 5aminoluvelinic acid. Photochem. Photobiol., 2000, 72(1), 128-134.

[108] Samkoe, K.S.; Cramb, D.T. Application of an ex ovo chicken chorioallantoic membrane model for two-photon excitation photodynamic therapy of age-related macular degeneration. J. Biomed. Opt., 2003, 8(3), 410-417.

[109] Samkoe, K.S.; Clancy, A.A.; Karotki, A.; Wilson, B.C.; Cramb, D.T. Complete blood vessel occlusion in the chick chorioallantoic membrane using two-photon excitation photodynamic therapy: implications for treatment of wet age-related macular degeneration. J. Biomed. Opt., 2007, 12, 034025-1 - 034025-14.

[110]Shen, X.; He, F.; Wu, J.; Xu, G.Q.; Yao, S.Q.; Xu, Q.-H. Enhanced two-photon singlet oxygen generation by photosensitizer-doped conjugated polymer nanoparticles. Langmuir, 2011, 27(5), 1739-1744.

[111]Idris, N.M.; Gnanasammandhan, M.K.; Zhang, J.; Ho, P.C.; Mahendran, R.; Zhang, Y. In vivo photodynamic therapy using upconversion nanoparticles as remote-controlled nanotransducers. Nat. Med., 2012, 18(10), 1580-1585.

[112] Skripka, A.; Valanciunaite, J.; Dauderis, G.; Poderys, V.; Kubiliute, R.; Rotomskis, R. Two-photon excited quantum dots as energy donors for photosensitizer chlorin e6. J. Biomed. Opt., 2013, 18(7), 078002.

[113]Rotomskis, R.; Valanciunaite, J.; Skripka, A.; Steponkiene, S.; Spogis, G.; Bagdonas, S.; Streckyte, G. Complexes of functionalized quantum dots and chlorin e6 in photodynamic therapy. Lith. J. Phys., 2013, 53(1), 57-68.

[114] Starkey, J.R.; Pascucci, E.M.; Drobizhev, M.A.; Elliott, A.; Rebane, A.K. Vascular targeting to the SST2 receptor improves the therapeutic response to near-IR two-photon activated PDT for deep-tissue cancer treatment. Biochim. Biophys. Acta, 2013, 1830(10), 4594-4603.

[115] Spangler, C.W.; Starkey, J.R.; Dubinina, G.; Fahlstrom, C.; Shepard, J. Optimization of targeted two-photon PDT triads for the treatment of head and neck cancers. Proc. SPIE, 2012, 8207, 820720.

[116] Spangler, C.W.; Starkey, J.R.; Liang, B.; Fedorka, S.; Yang, H.; Jiang, $\mathrm{H}$. Development of image-guided targeted two-photon PDT for the treatment of head and neck cancers. Proc. SPIE, 2014, 8931, 89310C.

[117]Zou, Q.; Zhao, H.; Zhao, Y.; Fang, Y.; Chen, D.; Ren, J.; Wang, X.; Wang, Y.; Gu, Y.; Wu, F. Effective two-photon excited photodynamic therapy of xenograft tumors sensitized by water-soluble bis(arylidene)cycloalkanone photosensitizers. J. Med. Chem., 2015, 58, $7949-7958$.

[118]Rustin, G.J.S.; Galbraith, S.M.; Anderson, H.; Stratford, M.; Folkes, L.K.; Sena, L.; Gumbrell, L.; Price, P.M. Phase I clinical trial of weekly combretastatin A4 phosphate: clinical and pharmacokinetic results. $J$. Clin. Oncol., 2003, 21(15), 2815-2822.

[119]Rustin, G.J.; Shreeves, G.; Nathan, P.D.; Gaya, A.; Ganesan, T.S.; Wang, D.; Boxall, J.; Poupard, L.; Chaplin, D.J.; Stratford, M.R.L.; Balkissoon, J.; Zweifel, M. A Phase Ib trial of CA4P (ciscombretastatin A-4 phosphate ), carboplatin, and paclitaxel in patients with advanced cancer. Br. J. Cancer, 2010, 102(9), 1355-1360.

[120]Bisby, R.H.; Botchway, S.W.; Hadfield, J.A; McGown, A.T.; Parker, A.W.; Scherer, K.M. Fluorescence lifetime imaging of E-combretastatin uptake and distribution in live mammalian cells. Eur. J. Cancer, 2012, 48(12), 1896-1903.

[121]Bisby, R.H.; Botchway, S.W.; Greetham, G.M.; Hadfield, J.A; McGown, A.T.; Parker, A.W.; Scherer, K.M.; Towrie, M. Timeresolved nanosecond fluorescence lifetime imaging and picosecond 
infrared spectroscopy of combretastatin A-4 in solution and in cellular systems. Meas. Sci. Technol., 2012, 23(8), 084001.

[122] Scherer, K.M.; Bisby, R.H.; Botchway, S.W.; Hadfield, J.A.; Parker, A.W. Anticancer phototherapy using activation of E-combretastatins by two-photon-induced isomerization. J. Biomed. Opt., 2015, 20(5), 51004.

[123] Görner, H.; Kuhn, H.J. Cis-trans photoisomerization of stilbenes and stilbene-like molecules. Adv. Photochem., 1995, 19, 1-117.

[124] Waldeck, D.H. Photoisomerization dynamics of stilbenes. Chem. Rev., 1991, 91, 415-436.

[125]Pettit, G.R.; Singh, S.B. Isolation, structure, and synthesis of combretastatin A-2, A-3, and B-2. Can. J. Chem., 1987, 65, 2390-2396.

[126]Hadfield, J.A.; McGown, A.T.; Mayalarp, S.P.; Land, E.J.; Hamblett, I.; Gaukroger, K.; Lawrence, N.J.; Hepworth, L.A.; Butler, J. Substituted stilbenes and their reactions. U.S. Patent US 7220784 B2, May 22, 2007.

[127] Scherer, K.M.; Bisby, R.H.; Botchway, S.W.; Hadfield, J.A.; Haycock, J.W.; Parker, A.W. Three-dimensional imaging and uptake of the anticancer drug combretastatin in cell spheroids and photoisomerization in gels with multiphoton excitation. J. Biomed. Opt., 2015, 20, 078003$1-078003-9$.

[128] Scherer, K.M.; Bisby, R.H.; Botchway, S.W.; Greetham, G.M.; Hadfield, J.A.; Parker, A.W.; Towrie, M. Spectroscopy and fluorescence lifetime imaging in live cells of a cyano-substituted combretastatin. Biomed. Spectrosc. Imaging, 2014, 3(3), 211-218.

[129]Cohanoschi, I.; Echeverría, L.; Hernández, F.E. Three-photon absorption measurements in hematoporphyrin IX: 'ground-breaking opportunities in deep photodynamic therapy'. Chem. Phys. Lett., 2006, 419(1-3), 33-36.

[130] Valentine, R.M.; Ibbotson, S.H.; Wood, K.; Brown, C.T.A.; Moseley, H. Modelling fluorescence in clinical photodynamic therapy. Photochem. Photobiol. Sci., 2013, 12(1), 203-213.

[131]Zaak, D.; Karl, A.; Knüchel, R.; Stepp, H.; Hartmann, A.; Reich, O.; Bachmann, A.; Siebels, M.; Popken, G.; Stief, C. Diagnosis of urothelial carcinoma of the bladder using fluorescence endoscopy. BJU Int., 2005, 96(2), 217-222.

[132] Stummer, W.; Pichlmeier, U.; Meinel, T.; Wiestler, O.D.; Zanella, F.; Reulen, H.-J. Fluorescence-guided surgery with 5-aminolevulinic acid for resection of malignant glioma: a randomised controlled multicentre phase III trial. Lancet Oncol., 2006, 7(5), 392-401.

[133]Johansson, A.; Palte, G.; Schnell, O.; Tonn, J.-C.; Herms, J.; Stepp, H. 5-Aminolevulinic acid-induced protoporphyrin IX levels in tissue of human malignant brain tumors. Photochem. Photobiol., 2010, 86(6), 1373-1378.

[134]Beck, T.J.; Kreth, F.W.; Beyer, W.; Mehrkens, J.H.; Obermeier, A.; Stepp, H.; Stummer, W.; Baumgartner, R. Interstitial photodynamic therapy of nonresectable malignant glioma recurrences using 5aminolevulinic acid induced protoporphyrin IX. Lasers Surg. Med., 2007, 39(5), 386-393.

[135]Johansson, A.; Faber, F.; Kniebühler, G.; Stepp, H.; Sroka, R.; Egensperger, R.; Beyer, W.; Kreth, F.-W. Protoporphyrin IX fluorescence and photobleaching during interstitial photodynamic therapy of malignant gliomas for early treatment prognosis. Lasers Surg. Med., 2013, 45(4), 225-234.

[136]Jocham, D.; Stepp, H.; Waidelich, R. Photodynamic diagnosis in urology: state-of-the-art. Eur. Urol., 2008, 53(6), 1138-1150.

[137]Gibbs-Strauss, S.L.; Samkoe, K.S.; O’Hara, J.A.; Davis, S.C.; Hoopes, P.J.; Hasan, T.; Pogue, B.W. Detecting epidermal growth factor receptor tumor activity in vivo during cetuximab therapy of murine gliomas. Acad. Radiol., 2011, 17(1), 7-17.

[138] Stummer, W.; Tonn, J.-C.; Goetz, C.; Ullrich, W.; Stepp, H.; Bink, A.; Pietsch, T.; Pichlmeier, U. 5-Aminolevulinic acid-derived tumor fluorescence: the diagnostic accuracy of visible fluorescence qualities as corroborated by spectrometry and histology and postoperative imaging. Neurosurgery, 2014, 74(3), 310-319.
[139] Mallidi, S.; Anbil, S.; Lee, S.; Manstein, D.; Elrington, S.; Kositratna, G.; Schoenfeld, D.; Pogue, B.; Davis, S.J.; Hasan, T. Photosensitizer fluorescence and singlet oxygen luminescence as dosimetric predictors of topical 5-aminolevulinic acid photodynamic therapy induced clinical erythema. J. Biomed. Opt., 2014, 19(2), 028001-1-028001-13.

[140] Ogura, S.; Yazaki, K.; Yamaguchi, K.; Kamachi, T.; Okura, I. Localization of poly-L-lysine-photosensitizer conjugate in nucleus. $J$. Control. Release, 2005, 103(1), 1-6.

[141] Spring, B.Q.; Abu-Yousif, A.O.; Palanisami, A.; Rizvi, I.; Zheng, X.; Mai, Z.; Anbil, S.; Sears, R.B.; Mensah, L.B.; Goldschmidt, R.; Erdem, S.S.; Oliva, E.; Hasan, T. Selective treatment and monitoring of disseminated cancer micrometastases in vivo using dual-function, activatable immunoconjugates. Proc. Natl. Acad. Sci. U. S. A., 2014, 111(10), 933-942.

[142] Abu-Yousif, A.O.; Moor, A.C.E.; Zheng, X.; Savellano, M.D.; Yu, W.; Selbo, P.K.; Hasan, T. Epidermal growth factor receptor-targeted photosensitizer selectively inhibits EGFR signaling and induces targeted phototoxicity in ovarian cancer cells. Cancer Lett., 2012, $321(2), 120-127$.

[143] Mitsunaga, M.; Ogawa, M.; Kosaka, N.; Rosenblum, L.T.; Choyke, P.L.; Kobayashi,H. Cancer cell-selective in vivo near infrared photoimmunotherapy targeting specific membrane molecules. Nat. Med., 2011, 17(12), 1685-1691.

[144] Mir, Y.; Elrington, S.A.; Hasan, T. A new nanoconstruct for epidermal growth factor receptor-targeted photo-immunotherapy of ovarian cancer. Nanomedicine Nanotechnology, Biol. Med., 2013, 9(7), 11141122 .

[145] Shi, C. Comment on "Rapid cancer detection by topically spraying a gglutamyltranspeptidase-activated fluorescent probe". Sci. Transl. Med., 2012, 4(121), 121le1.

[146]Bartusik, D.; Aebisher, D.; Ghogare, A.; Ghosh, G.; Abramova, I.; Hasan, T.; Greer, A. A fiberoptic (photodynamic therapy type) device with a photosensitizer and singlet oxygen delivery probe tip for ovarian cancer cell killing. Photochem. Photobiol., 2013, 89(4), 936-941.

[147]Yuan, A.; Laing, B.; Hu, Y.; Ming, X. Direct oligonucleotidephotosensitizer conjugates for photochemical delivery of antisense oligonucleotides. Chem. Commun., 2015, 51(30), 6678-6680.

[148]Botchway, S.W.; Coulter, J.A.; Currell, F.J. Imaging intracellular and systemic in vivo gold nanoparticles to enhance radiotherapy. $B r . J$. Radiol., 2015, 88, 1-13.

[149]Tong, R.; Chiang, H.H.; Kohane, D.S. Photoswitchable nanoparticles for in vivo cancer chemotherapy. Proc. Natl. Acad. Sci. U. S. A., 2013, 110(47), 19048-19053.

[150] Yang, C.; Liu, Q.; He, D.; Na, N.; Zhao, Y.; Ouyang, J. Dual-modal imaging and photodynamic therapy using upconversion nanoparticles for tumor cells. Analyst, 2014, 139(24), 6414-6420.

[151]Wu, X.; Chen, G.; Shen, J.; Li, Z.; Zhang, Y.; Han, G. Upconversion nanoparticles: a versatile solution to multiscale biological imaging. Bioconjug. Chem., 2015, 26, 166-175.

[152]Zhong, W.; Celli, J.P.; Rizvi, I.; Mai, Z.; Spring, B.Q.; Yun, S.H.; Hasan, T. In vivo high-resolution fluorescence microendoscopy for ovarian cancer detection and treatment monitoring. Br. J. Cancer, 2009, 101(12), 2015-2022.

[153] Glidden, M.D.; Celli, J.P.; Massodi, I.; Rizvi, I.; Pogue, B.W.; Hasan, T. Image-based quantification of benzoporphyrin derivative uptake, localization, and photobleaching in 3D tumor models, for optimization of PDT parameters. Theranostics, 2012, 2(9), 827-839.

[154] Anbil, S.; Rizvi, I.; Celli, J.P.; Alagic, N.; Pogue, B.W.; Hasan, T. Impact of treatment response metrics on photodynamic therapy planning and outcomes in a three-dimensional model of ovarian cancer. J. Biomed. Opt., 2013, 18(9), 098004.

[155]Celli, J.P.; Rizvi, I.; Blanden, A.R.; Massodi, I.; Glidden, M.D.; Pogue, B.W.; Hasan, T. An imaging-based platform for high-content, quantitative evaluation of therapeutic response in 3D tumour models. Nat. Sci. Reports, 2014, 4(3751), 1-10. 
[156]Demidova, T.N.; Hamblin, M.R. Effect of cell-photosensitizer binding and cell density on microbial photoinactivation. Antimicrob. Agents Chemother., 2005, 49(6), 2329-2335.

[157]Hamblin, M.R.; O’Donnell, D.A.; Murthy, N.; Contag, C.H.; Hasan, T.

Rapid control of wound infections by targeted photodynamic therapy

Received: March X, 2016 monitored by in vivo bioluminescence imaging. Photochem. Photobiol., 2002, 75(1), 51-57. 